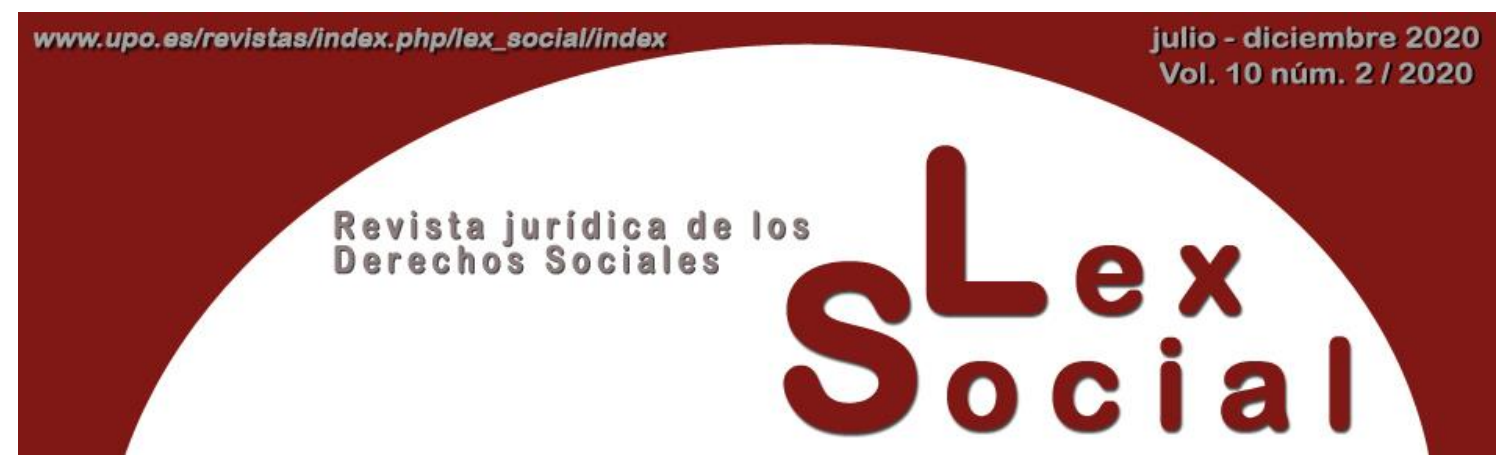

\title{
LA RESPONSABILIDAD DE LAS EMPRESAS EN EL SISTEMA DEL CONSEJO DE EUROPA*
}

\section{RESPONSIBILITY OF ENTERPRISES IN THE COUNCIL OF EUROPE SYSTEM}

TATSIANA USHAKOVA

Profesora Titular de Derecho del Trabajo y de la Seguridad Social

Universidad de Alcalá

Artículo recibido el 16 de mayo de 2020

Artículo aceptado el 29 de mayo de 2020

DOI: https://doi.org/10.46661/lexsocial.5068

\begin{abstract}
RESUMEN
El estudio contribuye a la reflexión sobre la posición de las empresas, y en especial las multinacionales, entre los sujetos y actores del Derecho internacional. Para describir dicha posición, se hace referencia a los elementos de la personalidad jurídica internacional, en particular, la capacidad de ser titular de los derechos y obligaciones conferidos por las normas internacionales. Se analizan las vías de la responsabilidad de las empresas por violación de los derechos humanos en el sistema del Consejo de Europa. Al respecto, proporciona el punto de partida el hecho de que, según el CEDH, las empresas puedan demandar ante el TEDH por vulneración de sus derechos. Parece coherente que dicha atribución tenga como contrapartida la responsabilidad por la violación de sus obligaciones en materia de derechos humanos.
\end{abstract}

\footnotetext{
* Este estudio se ha realizado en el marco del Proyecto financiado por el Ministerio de Economía y Competitividad, que lleva por título "Empresas multinacionales y normas internacionales del trabajo. Especial referencia a la situación en España" (DER2016-77973-R), y se ha presentado como ponencia en el Seminario internacional "Responsabilidad de las empresas multinacionales por vulneración de los estándares laborales: entre lo deseable y lo posible", celebrado el 16 de diciembre de 2019, en la Sala de Conferencias Internacionales de la Universidad de Alcalá.
} 
Palabras Clave: Responsabilidad de las empresas, empresas multinacionales, derechos humanos, CEDH, TEDH.

\begin{abstract}
This study contributes to the analysis of the business and, especially, multinational enterprises position, among the subjects and actors of International law. In order to describe this position, reference has been made to the elements of international legal personality, namely: the capacity to enforce one's own rights and to be subject of obligations under International law. Particular attention has been payed to the ways of responsibility of companies for human rights' violation in the Council of Europe System. In this regard, the capacity of companies to bring claims before the ECtHR, which is provided by the ECHR, has been taken as a starting point. It seems coherent that this attribution has as a counterpart the capacity to be responsible for the breach of their obligations on human rights.
\end{abstract}

KEYWORDS: Responsibility of enterprises, multinational enterprises, human rights, ECHR, ECtHR.

SUMARIO

1. Introducción.

2. La personalidad jurídica internacional y las empresas.

3. La capacidad de hacer valer los derechos.

4. La responsabilidad por violación de los derechos.

5. Las manifestaciones de la responsabilidad en la práctica del TEDH.

6. Conclusiones.

7. Bibliografía.

\title{
1. Introducción.
}

Al comienzo del siglo XXI, uno de los puntos de inflexión en el debate jurídico es la relación entre la protección de los derechos humanos y el compromiso al respecto de los centros de poder económico. Actualmente, las entidades económicas más importantes en su conjunto son las compañías cuya actividad traspasa las fronteras nacionales ${ }^{1}$. En este

\footnotetext{
${ }^{1}$ Según los datos del Banco Mundial, actualizados por la ONG Global Justice Now (conocida antes como World Development Movement), en 2018, las empresas multinacionales constituyen 69 de entre las 100 entidades económicas más importantes del mundo, superando el poder económico de los Estados desarrollados. Además, la proporción aumenta de manera significativa si el punto de partida son las 200 entidades. En este supuesto, las empresas llegan al número de 157. Véase la tabla en: https://www.globaljustice.org.uk/news/2018/oct/17/69-richest-100-entities-planet-are-corporations-notgovernments-figures-show (consultado el 18 de marzo de 2020).
} 
sentido, cabe esperar que dicha influencia se manifieste en una mayor responsabilidad en el plano internacional.

Como punto de partida, la Declaración Universal de Derechos Humanos (DUDH), de $1948^{2}$, ofrece el fundamento jurídico para la conexión entre los derechos humanos y las obligaciones de las empresas, al incluir el derecho de toda persona a que se establezca un orden social e internacional en que los derechos y libertades proclamados se hagan plenamente efectivos (art. 28), y al afirmar que "tanto los individuos como las instituciones" tienen la obligación de promover el respeto de los derechos humanos y asegurar, por medidas progresivas de carácter nacional e internacional, su reconocimiento y aplicación universales y efectivos (Preámbulo). Aun así, esta obligación parte del deber de los pueblos y naciones de esforzarse en esta dirección.

Es cierto que, tradicionalmente, la protección de los derechos humanos se ha vinculado a la acción normativa estatal. En el plano nacional, dicha protección se ha asegurado mediante el desarrollo normativo de las garantías constitucionales, y en el plano internacional, mediante los tratados internacionales de derechos humanos suscritos por los Estados. En el ámbito europeo, uno de los sistemas de protección más desarrollados es el del Consejo de Europa, con el núcleo en el Convenio Europeo para la Protección de los Derechos Humanos y las Libertades Fundamentales (CEDH) ${ }^{3}$.

Sin embargo, hoy en día, la pretensión universalista de los derechos humanos hace trascender las fronteras nacionales y puede realizarse solo en el marco de una comunidad internacional abierta e inclusiva ${ }^{4}$. Se cuestiona la hegemonía del Estado nacional como sujeto más representativo en el mundo globalizado, debido al auge de otros actores relevantes en el plano internacional, tales como las organizaciones no gubernamentales (ONG), las confederaciones sindicales o las empresas multinacionales (EMN) ${ }^{5}$.

\footnotetext{
Véase también un análisis comparado entre el volumen de ventas anuales de ciertas empresas transnacionales y el Producto Interior Bruto de algunos Estados, que realiza AIRA GONZÁLEZ, Patricia, "Reflexiones jurídicas en torno a la consideración de la empresa multinacional como sujeto del derecho internacional", Revista de Derecho de la UNED, n 20 (2017), pp. 237-261.

Asimismo, para el análisis actualizado de las economías estatales, véase IMF, World Economic Outlook, January 2020.

${ }^{2}$ Sobre la DUDH, que celebra su $70^{\circ}$ aniversario, véase, entre otros, PRONER, Carol; OLÁSOLO, Héctor; VILLÁN DURÁN, Carlos; RICOMB, Giselle, y BACK, Charlotte (Coords.), $70^{\circ}$ aniversario de la Declaración Universal de Derechos Humanos. La protección internacional de los derechos humanos en cuestión, Tirant lo Blanch, Valencia, 2018.

${ }^{3}$ El CEDH, de 4 de noviembre de 1950 (ETS n ${ }^{\circ}$ ), se modificó por los protocolos núms. 11 y 14, y se complementó por los protocolos núms. 1, 4, 6, 7, 12, 13 y 16 . Véase el texto en: https://www.echr.coe.int/Pages/home.aspx? $\mathrm{p}=$ basictexts\&c $=$ (visitado el 20 de marzo de 2020).

${ }^{4}$ HABERMAS, Jurgen, The Crisis of the European Union. A Response, Polity Press, Cambridge, 2012, p. 93.

${ }^{5}$ En este estudio, se opta por el término "empresa multinacional", siguiendo la elección de Muchlinski (MUCHLINSKI, Peter T., Multinational Enterprises and the Law, $2^{\text {nd }}$ Ed., Oxford University Press, Oxford, 2007), y el razonamiento de Karavias. Este último explica que "[t]he content of the terms 'multinational enterprise' and 'transnational corporation' remain contested. The terms have been employed by various authors and bodies to denote a variety of corporate structures. Ultimately, neither of the two terms has a fixed meaning in international law, and the use of one over the other remains a matter of taste". KARAVIAS, Markos, "Shared Responsibility and Multinational Enterprises", Neth Int Law Rev, 62 (2015), p. 95 .
} 
En este contexto, los derechos humanos pueden jugar un papel importante en el diseño de un orden internacional deseable, pero precisan especificar las medidas institucionales y los principios necesarios para exigir la responsabilidad de las entidades económicas que operan más allá del alcance de un poder democrático ${ }^{6}$. Así, las empresas multinacionales tienen obligaciones, al menos, para con sus empleados, a saber, deben garantizar la protección de los cuatro derechos fundamentales en el trabajo, reconocidos internacionalmente ${ }^{7}$, y unas condiciones laborales justas; para con las personas afectadas por su actividad y para con los grupos y colectivos más vulnerables ${ }^{8}$.

\section{La personalidad jurídica internacional y las empresas.}

Para apreciar el papel de las empresas en el plano jurídico internacional, es necesario hacer referencia al concepto de la personalidad jurídica internacional ${ }^{9}$. De manera dialéctica, este concepto se conecta con la posibilidad de hacer valer los derechos y de responder por la violación de los mismos ante los órganos internacionales competentes ${ }^{10}$, en el contexto de este estudio, ante los órganos internacionales de protección de los derechos humanos.

El carácter dialéctico o, en palabras de Brownlie, circular de dicha relación se debe a la necesidad de que los derechos que la componen tienen que realizarse en la práctica ${ }^{11}$. De este modo, el hecho de estar en posesión de la personalidad jurídica internacional significa tener la legitimación activa y pasiva ante los órganos internacionales, pero, al mismo tiempo, la existencia de esta legitimación, explícitamente prevista en los tratados de

\footnotetext{
${ }^{6}$ HABERMAS, Jurgen, Facticidad y validez. Sobre el Derecho y el Estado democrático de Derecho en términos de teoría del discurso, Trotta, Madrid 2008; GARRIDO GÓMEZ, María Isabel, las Transformaciones del Derecho en la Sociedad Global, Thomson Reuters, Aranzadi, Cizur Menor, 2010, pp. 163-164.

${ }^{7}$ Se trata de los derechos fundamentales en el trabajo protegidos en los ocho convenios fundamentales de la OIT [El Convenio sobre el trabajo forzoso, 1930 (núm. 29); el Convenio sobre la libertad sindical y la protección del derecho de sindicación, 1948 (núm. 87); el Convenio sobre el derecho de sindicación y de negociación colectiva, 1949 (núm. 98); el Convenio sobre igualdad de remuneración, 1951 (núm. 100); el Convenio sobre la abolición del trabajo forzoso, 1957 (núm. 105); el Convenio sobre la discriminación (empleo y ocupación), 1958 (núm. 111); el Convenio sobre la edad mínima, 1973 (núm. 138), y el Convenio sobre las peores formas de trabajo infantil, 1999 (núm. 182)], y recogidos en la Declaración de la OIT relativa a los principios y derechos fundamentales en el trabajo de 1998. Véase, al respecto, el VI Informe sobre los Principios y derechos fundamentales en el trabajo: Retos y oportunidades, $106^{a}$ reunión de la Conferencia Internacional del Trabajo, Oficina Internacional del Trabajo, Ginebra 2017.

8 "The role of transnational corporations", in The Role of Non-State Entities, Icelandic Human Rights Centre, disponible en: http://www.humanrights.is/en/human-rights-education-project/human-rightsconcepts-ideas-and-fora/human-rights-actors/the-role-of-non-state-entities (consultado el 20 de marzo de 2020).

${ }^{9}$ NIJMAN, Janne E., The Concept of International Legal Personality: An Inquiry into the History and Theory of International Law, T.M.C. Asser Press, The Hague, 2004; PORTMANN, Roland, Legal Personality in International law, Cambridge University Press, Cambridge, 2010; CRAWFORD, James, Brownlie's Principles of Public International Law, $8^{\text {th }}$ Ed., Oxford University Press, Oxford, 2012, pp. 115126.

${ }^{10}$ CRAWFORD, op. cit, p. 115.

11 Ibid.
} 
derechos humanos y ejercitada en virtud de los mismos, permite constatar la existencia del sujeto de Derecho internacional.

En su Dictamen histórico de 1949, la Corte Internacional de Justicia de ONU (CIJ) señaló que el concepto de la personalidad internacional no está claramente definido y da lugar a controversias $^{12}$. De hecho, en aquel momento, solo los Estados se consideraban como sujetos del Derecho internacional y, por lo tanto, poseedores de la personalidad jurídica internacional en todas sus manifestaciones. Sin embargo, el Dictamen citado abrió el camino para el reconocimiento de la personalidad jurídica internacional de otros entes, a saber, de las organizaciones internacionales intergubernamentales (OO.II.), y, más en concreto, de las Naciones Unidas (ONU). A partir del Dictamen citado, se reconoció a las OO.II. la personalidad jurídica limitada a sus competencias, esto es, la personalidad jurídica funcional. Así las cosas, la doctrina jurídica equipara la subjetividad internacional (el hecho de ser sujeto de Derecho internacional) y la personalidad jurídica internacional.

Los Estados, sujetos plenos, cuentan con todos los elementos de la subjetividad:

- hacer valer sus derechos en el plano internacional;

- responder por sus obligaciones internacionales;

- disponer de los privilegios e inmunidades en el plano internacional, y

- participar en el proceso de creación de las normas internacionales.

Con todo, puede afirmarse que los sujetos indudables del Derecho internacional son los Estados y las OO.II., pero, junto con ellos, existen otros actores o, si se quiere, sujetos con la personalidad jurídica restringida, que reúnen algunos de los elementos mencionados. Estos actores o sujetos son: los pueblos, ciertas entidades vinculadas a la actividad religiosa, los grupos con estatuto de beligerantes y las personas privadas, entre ellas, las personas físicas (individuos) y las personas jurídicas (las ONGs y las empresas) $)^{13}$.

Según la visión tradicional, los Estados, sujetos plenos, atribuyen la capacidad jurídica a otros sujetos o actores en el plano internacional ${ }^{14}$. No obstante, existen muchas otras teorías, cuyo propósito consiste en legitimar la existencia de facto de otros sujetos ${ }^{15}$. Si la visión clásica y tradicional centraliza los poderes en los Estados, la visión pragmática constata el debilitamiento del Estado y la aparición de otros entes de poder, incluidos las empresas y, en particular, las empresas multinacionales, con competencias adquiridas

\footnotetext{
${ }^{12}$ ICJ, Reparation of Injuries Suffered in the Service of the United Nations, Advisory Opinion, 1949 ICJ Reports 174, p. 178.

${ }^{13}$ DIEZ DE VELASCO, Manuel, Instituciones de Derecho Internacional Público, $17^{\mathrm{a}}$ ed., Tecnos, Madrid, 2009 , pp. 292 y ss.

${ }^{14}$ HICKEY Jr., James E., "The Source of International Legal Personality in the $21^{\text {st }}$ Century", 2 Hofstra L.\&Pol'y Symp 1 (1997), pp. 12-14.

${ }^{15}$ En su estudio al respecto, Portmann señala cinco teorías diferentes relativas a la personalidad jurídica internacional: "Five different conceptions on international personality are identified as being present in international legal argument: the 'states-only conception', the 'recognition conception', the 'individualistic conception', the 'formal conception' and the 'actor conception'”. PORTMANN, op. cit., p. 2.
} 
debido a su creciente papel en el panorama internacional ${ }^{16}$. Podría afirmarse que, por un lado, la soberanía del Estado se presenta como un impedimento a la ordenación racional de la comunidad internacional, y, por otro, el Estado resulta insuficiente para dar respuesta a las exigencias y necesidades de dicha comunidad. De este modo, desde hace varias décadas, se ha iniciado un proceso de "desmontaje pacífico del Estado" por obra de otros sujetos y actores ${ }^{17}$.

La idea ya estaba latente en el Dictamen de 1949, cuando se señalaba que "los sujetos de Derecho no son necesariamente idénticos en cuanto a su naturaleza o la existencia de sus derechos"18, y que "el crecimiento progresivo de las actividades colectivas de los Estados ha hecho surgir ejemplos de acciones ejercidas en el plano internacional por determinadas entidades que no son Estados" "19. Así, las cosas, la naturaleza de los sujetos se conectó, de manera pragmática, con las necesidades de la comunidad internacional.

Volviendo al análisis inicial de los cuatro elementos de la personalidad jurídica internacional, cabe constatar la presencia de algunos de ellos en el supuesto de las empresas.

En primer lugar, el art. 34 del CEDH y la jurisprudencia del Tribunal Europeo de Derechos Humanos (TEDH) reconoce la legitimación activa o la capacidad de hacer valer sus derechos a todo tipo de empresas, incluidas las multinacionales.

En el plano internacional universal, cabe hacer referencia a los instrumentos de arbitraje mixto, que permiten a las empresas o a los inversores plantear reclamaciones contra el Estado. Por ejemplo, en el contexto del caso Yukos, no solo hubo una demanda de la compañía como tal, en virtud del Convenio Europeo, sino también otras demandas de los inversores, de conformidad con el Tratado de la Carta de la Energía (TCE), y de los acuerdos de promoción y protección recíproca de inversiones (APPRIs) ${ }^{20}$.

En segundo lugar, resulta más difícil concebir la responsabilidad directa de las empresas por violación de los derechos humanos en el plano internacional. Habría que referirse a la responsabilidad indirecta, esto es, asegurada por los Estados en el ámbito nacional, o a la responsabilidad voluntaria, de acuerdo con los instrumentos de soft law (códigos de

\footnotetext{
${ }^{16}$ HERNÁNDEZ ZUBIZARRETA, Juan, Las empresas transnacionales y los derechos humanos: Historia de una simetría normativa. De la responsabilidad social corporativa a las redes contra hegemónicas transnacionales, Hegoa, Bilbao, 2009, pp. 75 y ss.

${ }^{17}$ RODRÍGUEZ CARRIÓN, Alejandro, "El Derecho International en el umbral del siglo XXI", Lección Inaugural del curso 1999-2000 pronunciada en la Universidad de Málaga, pp.16-18, citado por ANDRÉS SÁENZ DE SANTA MARÍA, Paz, "Las dinámicas del Derecho internacional en el siglo XXI: acordes y desacordes", en MARTÍN Y PÉREZ DE NANCLARES, José (Coord.), Estados y organizaciones internacionales ante las nuevas crisis globales, AEPDIRI, Iustel, Universidad de Rioja, 2010, p. 82.

${ }^{18}$ ICJ, Reparation of Injuries Suffered in the Service of the United Nations, Advisory Opinion, 1949 ICJ Reports 174, p. 178.

${ }^{19} \mathrm{Ibid}$. Véase también, USHAKOVA, Tatsiana, "La OIT como una organización internacional dinámica en el sistema de Derecho internacional", en GIL Y GIL, José Luis (Dir.), España y la OIT. 100 años de diálogo en un mundo cambiante, Ediciones Cinca, Madrid, 2017, pp. 61 y ss.

${ }^{20}$ Véase, al respecto, USHAKOVA, Tatsiana, "El caso Yukos desde la óptica multidimensional, con especial referencia a los problemas de competencia", Revista de arbitraje comercial y de inversiones, Vol. VIII, $\mathrm{n}^{\circ} 1$ (2015), pp. 143 y ss.
} 
conducta o principios rectores). En el sistema del Consejo de Europa, se han adoptado la Declaración del Comité de Ministros sobre los Principios Rectores de la ONU, de $2014^{21}$, y la Recomendación sobre los derechos humanos y las empresas, de $2016^{22}$, para asegurar la responsabilidad de las empresas mediante la implementación de los Principios Rectores de la ONU, de $2011^{23}$.

En el marco de la ONU, el Consejo de Derechos Humanos (CDH) estableció el Grupo de Trabajo intergubernamental, con el mandato de elaborar un instrumento jurídicamente vinculante para regular las actividades de las empresas transnacionales y otras empresas con respecto a los derechos humanos, tal y como se prevé en su Resolución 26/9, de $2014^{24}$. El término "otras empresas" se refiere a todas las empresas cuyas actividades operacionales tienen carácter transnacional, y no se aplica a las empresas registradas a nivel local, con arreglo a la legislación nacional pertinente ${ }^{25}$. Para ilustrar el escaso acuerdo entre los Estados para concebir un tratado sobre este particular, cabe señalar que la Resolución 26/9 se aprobó con catorce votos en contra y trece abstenciones. Entre los adversarios, se encontraban algunos Estados miembros de la UE, Estados Unidos y Japón.

Hay que señalar que el proyecto de tratado revisado, de $2019^{26}$, contiene modificaciones importantes en comparación en el llamado "borrador cero". Entre los cambios relevantes, cabe destacar un alcance más amplio, que abarca a toda actividad comercial, y no solo la de carácter transnacional, aunque el acento sigue recayendo en las empresas con actividades transnacionales (art. 3.1); e incluye todos los derechos humanos (art. 3.3).

Asimismo, cabría plantear la responsabilidad de las empresas en el Derecho Penal Internacional $^{27}$. El Estatuto de la Corte Penal Internacional contempla la responsabilidad de los individuos por los crímenes de guerra y de lesa humanidad. En esta misma línea, podría concebirse la responsabilidad penal de las empresas por las violaciones más graves

\footnotetext{
${ }^{21}$ Declaración del Consejo de Ministros sobre los Principios Rectores de la ONU, aprobada el 16 de abril de 2014, en la reunión n 1197 de los Delegados de Ministros.

${ }^{22}$ Recommendation CM/Rec (2016)3 of the Committee of Ministers to Member States, Human Rights and Business, adopted on 2 March 2016, Council of Europe, Strasburg 2016, disponible en: https://edoc.coe.int/en/fundamental-freedoms/7302-human-rights-and-business-recommendationcmrec20163-of-the-committee-of-ministers-to-member-states.html (consultado el 3 de abril de 2020).

${ }^{23} \mathrm{UN}$, Principios Rectores sobre las empresas y los derechos humanos: puesta en práctica del marco de las Naciones Unidas para "proteger, respetar y remediar", Anexo al Informe del Representante Especial del Secretario General de la ONU para la cuestión de los derechos humanos y las empresas transnacionales y otras empresas, John Ruggie, 21 de marzo de 2011, Consejo de Derechos Humanos, 17. ${ }^{\circ}$ período de sesiones, UN Doc. A/HRC/17/31. El Consejo de Derechos Humanos hizo suyos los Principios Rectores en su Resolución 17/4, de 16 de junio de 2011.

${ }^{24}$ UN Doc. A/HRC/26/L.22/Rev1, adoptada el 26 de junio de 2014.

${ }^{25}$ UN Doc. A/HRC/26/L.22/Rev1, p. 2.

${ }^{26}$ Grupo de Trabajo Intergubernamental de Composición Abierta sobre las Empresas Trasnacionales y Otras Empresas Comerciales en material de Derechos Humanos (OEIGWG), Proyecto revisado de un instrumento internacional jurídicamente vinculante sobre las empresas transnacionales y otras empresas con respecto a los derechos humanos, de 16 de julio de 2019, disponible en: https://www.ohchr.org/Documents/HRBodies/HRCouncil/WGTransCorp/OEIGWG_RevisedDraft_L BI.pdf. (consultado el 20 de abril de 2020).

${ }^{27}$ WORSTER, William T., "Relative International Legal Personality of Non-State Actors", Brook. J. Int'l L., Vol. 42, n' 1(2016), pp. 244-245.
} 
de los derechos humanos, entre otros, en los supuestos de la trata de personas, la tortura, la esclavitud o el trabajo forzoso.

Los Estados deberían incorporar a su legislación la responsabilidad penal de las personas jurídicas ${ }^{28}$. También habría que universalizar el principio de la doble imputación, es decir, las sociedades transnacionales serían responsables penalmente por los crímenes y delitos que cometen, al igual que los dirigentes que, de conformidad con los estatutos de la sociedad y con su voto afirmativo o por omisión, aprueban las decisiones incriminadas. En este sentido, podría servir de referencia el art. 18 del Convenio penal sobre la corrupción, de $1999^{29}$, que establece la responsabilidad penal de las personas jurídicas y el principio de la doble imputación.

${ }^{28}$ En España, desde la reforma del Código Penal por la Ley Orgánica 5/2010, de 22 de junio (BOE ${ }^{\circ} 152$, de 23 de junio de 2010), las personas jurídicas también están sujetas a responsabilidad penal, por una doble vía. Según el art. 31 bis del CP, las personas jurídicas serán responsables penalmente:

a) De los delitos cometidos en nombre o por cuenta de las mismas, y en su beneficio directo o indirecto, por sus representantes legales o por aquellos que actuando individualmente o como integrantes de un órgano de la persona jurídica, están autorizados para tomar decisiones en nombre de la persona jurídica u ostentan facultades de organización y control dentro de la misma.

b) De los delitos cometidos, en el ejercicio de actividades sociales y por cuenta y en beneficio directo o indirecto de las mismas, por quienes, estando sometidos a la autoridad de las personas físicas mencionadas en el párrafo anterior, han podido realizar los hechos por haberse incumplido gravemente por aquéllos los deberes de supervisión, vigilancia y control de su actividad atendidas las concretas circunstancias del caso.

$[\ldots]$.

Así, “...se añade la responsabilidad por aquellas infracciones propiciadas por no haber ejercido la persona jurídica el debido control sobre sus empleados, naturalmente con la imprescindible consideración de las circunstancias del caso concreto a efectos de evitar una lectura meramente objetiva de esta regla de imputación.

Se deja claro que la responsabilidad penal de la persona jurídica podrá declararse con independencia de que se pueda o no individualizar la responsabilidad penal de la persona física". L.O. 5/2010, Preámbulo, Capítulo VII, párrs. 2 y 3.

La reforma introducida por la Ley Orgánica 1/2015, de 30 de marzo (B.O.E. núm. 77, de 31 de marzo de 2015) lleva a cabo una mejora técnica en la regulación de la responsabilidad penal de las personas jurídicas. Existe una lista de más de veinte delitos imputables a la empresa: desde cuestiones como el tráfico ilegal de órganos hasta la financiación del terrorismo. Sin embargo, no quedan claros los criterios seguidos para la elección de estos supuestos y la exclusión de otros. De hecho, resulta sorprendente que se prevea una responsabilidad penal de la persona jurídica por casos poco probables como los relacionados con pornografía infantil, y queden fuera los delitos contra los derechos de los trabajadores.

${ }^{29}$ El Convenio Europeo, de 27 de enero de 1999 (ETS n ${ }^{\circ} 173$ ), entró en vigor el 1 de julio de 2002. Actualmente, está ratificado por todos los Estados miembros del Consejo de Europa.

Artículo 18. Responsabilidad de las personas jurídicas:

1. Cada Parte adoptará las medidas legislativas y de otra índole que sean necesarias para garantizar que se pueda hacer responsables a las personas jurídicas de los delitos de corrupción activa, de tráfico de influencias y de blanqueo de capitales tipificados de conformidad con el presente Convenio, cuando sean cometidos en beneficio de aquéllas por una persona física, actuando individualmente o como miembro de un órgano de la persona jurídica, que ejerza un poder directivo dentro de ésta, sobre la base de:

un poder de representación de la persona jurídica; o

una autoridad para adoptar decisiones en nombre de la persona jurídica; o

una autoridad para ejercer control en el seno de la persona jurídica;

así como de la participación de esa persona física en calidad de cómplice o de instigador en la comisión de los delitos anteriormente mencionados.

2. Aparte de los casos ya previstos en el apartado 1, cada Parte adoptará las medidas necesarias para garantizar que se pueda hacer responsable a una persona jurídica cuando la falta de vigilancia o de control por parte de una de las personas físicas a que se refiere el apartado 1 haya hecho posible la comisión, por 
En tercer lugar, por lo que respecta a los privilegios e inmunidades en el plano internacional, las empresas mutatis mutandis pueden beneficiarse de dichos privilegios derivados de las concesiones del Estado o de los acuerdos con los Estados, que fijan las condiciones más beneficiosas, entre otras, las exenciones fiscales. Sirva de ejemplo la sociedad "Eurofirma", establecida para la financiación de materia ferroviario, según lo estipulado en un Convenio, de 1955, con la participación de 14 Estados $^{30}$. Las Partes en el acuerdo reconocieron el estatus particular de la empresa, de conformidad del Derecho suizo, en sus sistemas legales correspondientes. Eurofirma se benefició de privilegios en el plano internacional, incluida la exención del régimen fiscal de Suiza, el Estado donde se había constituido.

Por último, y en relación con la posibilidad de crear normas internacionales, los acuerdos que suscriben las compañías con los Estados tienen una naturaleza bastante compleja, como pone de manifiesto el caso de Eurofirma. Sin embargo, hay que subrayar que este supuesto puede servir de ejemplo, como algún otro caso concreto, pero no para generalizar la situación de las empresas multinacionales. Más bien, con carácter general, las empresas no se consideran como sujetos del Derecho internacional. Por ejemplo, en el asunto Anglo-Iranian Oil Company, la Corte Internacional de Justicia de la ONU (CIJ) no reconoció el acuerdo entre la compañía y el Estado como tratado internacional ${ }^{31}$.

Hoy en día, las empresas pueden participar en el proceso de creación de las normas internacionales mediante los instrumentos del diálogo social, y a través de las asociaciones empresariales. La OIT proporciona un foro perfecto para materializar dicha participación.

\section{La capacidad de hacer valer los derechos.}

Actualmente, se da la paradoja de que el poder económico y político de las empresas multinacionales es superior al de la mayoría de Estados y de OO.II., sujetos de Derecho internacional reconocidos, $\mathrm{y}$, al mismo tiempo, son actores que reúnen menos elementos de la subjetividad internacional. En este sentido, y volviendo a la relación dialéctica entre

parte de una persona física sometida a su autoridad, de los delitos mencionados en el apartado 1 en beneficio de dicha persona jurídica.

3. La responsabilidad de la persona jurídica en virtud de los apartados 1 y 2 no excluye la acción penal contra las personas físicas autoras, instigadoras o cómplices de los delitos mencionados en el apartado 1.

${ }^{30}$ Véase Convenio relativo a la constitución de "Eurofima", Sociedad Europea para la Financiación de Material Ferroviario y Protocolo Adicional, hechos en Berna el 20 de octubre de 1955; Estatutos de la Sociedad europea para la financiación de material ferroviario, adoptados por la Asamblea general el 20 de noviembre de 1956, incluyendo las enmiendas adoptadas el 27 de febrero de 1962, que entraron en vigor el 1 de junio de 1962; las enmiendas adoptadas el 26 de febrero de 1970, que entraron en vigor el 10 de junio de 1970; las enmiendas adoptadas el 19 de febrero de 1976, que entraron en vigor el 11 de junio de 1976, y las enmiendas adoptadas el 1 de febrero de 1984, que entraron en vigor el 10 de mayo de 1984. BOE $\mathrm{n}^{\circ}$ 287, de 30 de noviembre de 1984, y posteriores modificaciones de los Estatutos, por ejemplo, la modificación debida a la ampliación de la participación de los ferrocarriles del Estado Húngaro S.A. (MVA) en el capital por acciones de Eurofirma, y la correspondiente modificación del art. 5 de los Estatutos, hecho en Santiago de Compostela el 23 de junio de 2006. BOE, nº 65, de 16 de marzo de 2007.

${ }^{31}$ ICJ, Anglo-Iranian Oil Company (U.K. v. Iran), Judgment of 22 July 1952, 1952 ICJ Reports, 93, p. 112. Véase, también, WORSTER, Loc. cit., p. 244. 
el reconocimiento de los elementos de la subjetividad jurídica internacional y la existencia de dicha subjetividad, hay que subrayar que el sistema del Consejo de Europa es el que más acentúa la presencia de, al menos, uno de estos elementos en el supuesto de las empresas: esto es, reconoce la legitimación activa de las empresas ante el Tribunal Europeo de Derechos Humanos ${ }^{32}$.

En efecto, el art. 34 "Demandas individuales" del CEDH permite al Tribunal conocer de una demanda presentada por una empresa por violación de los derechos y las libertades reconocidas en el Convenio y en sus Protocolos. El artículo reza:

\begin{abstract}
El Tribunal podrá conocer de una demanda presentada por cualquier persona física, organización no gubernamental o grupo de particulares que se considere víctima de una violación por una de las Altas Partes Contratantes de los derechos reconocidos en el Convenio o sus Protocolos. Las Altas Partes Contratantes se comprometen a no poner traba alguna al ejercicio eficaz de este derecho.
\end{abstract}

En primer lugar, hay que constatar que se trata del acceso directo al TEDH, facilitado tras la entrada en vigor del Protocolo $n^{\circ} 11$ en $1998^{33}$. Con anterioridad, el Tribunal actuaba junto con la Comisión, que decidía sobre la admisibilidad de la demanda. El procedimiento señalado de doble filtro sigue operativo en el Sistema Interamericano de Derechos Humanos.

En segundo lugar, el sistema del CEDH acoge un concepto amplio de persona legitimada, que comprende personas físicas, grupos de personas y organizaciones no gubernamentales. Aunque no se mencionan explícitamente, las empresas se ubican entre las "organizaciones no gubernamentales" 34 . Al respecto, es interesante recordar que la fórmula ha cambiado en varias ocasiones: inicialmente, el Convenio se refería a "cualquier persona natural o corporativa"; posteriormente, aludía al "órgano corporativo" y, finalmente, optó por la redacción actual ${ }^{35}$.

También es amplio el concepto de empresas demandantes. En efecto, cualquier tipo de empresa puede presentar la demanda, con el único requisito limitador de no ser un órgano de Estado. En este sentido, el TEDH precisó que las entidades de Derecho público pueden considerarse como ONGs en el sentido del Convenio, siempre y cuando no ejerciten poderes gubernamentales, no lleven a cabo funciones de las autoridades públicas y

\footnotetext{
${ }^{32}$ Véase, al respecto, ADDO, Michael K., "The Corporation as a Victim of Human Rights Violations", in ADDO, Michael K. (Ed.), Human Rights Standards and the Responsibility of Transnational Corporations, Kluwer Law International, The Hague, 1999, pp. 194 y ss.

${ }^{33}$ El Protocolo $\mathrm{n}^{\circ} 11$ (ETS n $\left.{ }^{\circ} 155\right)$ se adoptó el 11 de mayo de 1994 y entró en vigor el 1 de noviembre de 1998.

${ }^{34}$ En sus instrucciones sobre la aplicación del art. 34, el Tribunal menciona las personas jurídicas como sujetos legitimados, y precisa que se trata de las empresas, las ONGs y las asociaciones. Véase Rules of Court of 1 January 2020, Practice Directions, párr.8, disponible en: https://www.echr.coe.int/Documents/PD_institution_proceedings_ENG.pdf (consultado el 10 de abril de 2020).

${ }^{35}$ EMBERLAND, Marius, The Human Rights of Companies: Exploring the Structure of ECHR Protection, Oxford University Press, Oxford 2006; VAN DEN MUIJSENBERGH, Winfried H.A.M. and REZAI, Sam, "Corporations and European Convention on Human Rights", 25 Pac. McGeorge Global Bus. \& Dev. L.J. (2012), p. 48.
} 
resulten independientes del Estado ${ }^{36}$. La amplitud señalada se refuerza tanto en el art. 1, como en la última línea del art. 34. El art.1 obliga a los Estados contratantes a reconocer los derechos del Convenio a cualquier persona bajo su jurisdicción, lo que suprime, por ejemplo, el requisito de la nacionalidad. A su vez, la última línea del art. 34 contiene el compromiso de no poner traba alguna al ejercicio efectivo del derecho a la demanda.

En tercer lugar, la empresa tiene que ser víctima de una violación de los derechos reconocidos en el Convenio y en sus Protocolos. En este sentido, algunos derechos no plantean ningún problema, debido a la naturaleza "corporativa" de los sujetos legitimados, mientras que otros suponen ciertos obstáculos a la hora de alegarse por los mismos ${ }^{37}$.

Los derechos y las libertades fundamentales que pueden invocarse con éxito por las empresas son, ante todo, los derechos procesales y, en general, son los siguientes:

- obligación de respetar los derechos humanos (art. 1)

- derecho a un proceso equitativo (art. 6)

- no hay pena sin ley (art. 7)

- libertad de reunión y de asociación (art. 11)

- derecho a un recurso efectivo (art. 13)

- prohibición de discriminación (art. 14)

- derecho a la propiedad (art. 1 del Protocolo $\mathrm{n}^{\mathrm{o}}$ 1).

Si la mayoría de los derechos citados no hacen distinción entre las personas físicas y privadas y contienen la garantía general para con "toda persona", o la formula negativa "nadie podrá ser privado...", el art. 1 del Protocolo $n^{\circ} 1$ asegura la protección de los bienes de "toda persona física o moral"38.

Así, casi todos los derechos mencionados se alegaron por la empresa en el asunto Yukos c. Rusia ${ }^{39}$. En su momento, fue una de las compañías petroleras más importantes del mundo, con el valor añadido de que, en aquel entonces, las petroleras lideraban las listas de las EMNs de mayor poder económico ${ }^{40}$. No obstante, dejó de existir tras el procedimiento concursal y la condena de sus dirigentes por delitos fiscales.

\footnotetext{
${ }^{36}$ Sobre este aspecto, véase VAN KEMPEN, Piet Hein, "Human Rights and Criminal Justice Applied to Legal Persons. Protection and Liability of Private and Public Juristic Entities under the ICCPR, ECHR, ACHR and AfChHPR", Electronic Journal of Comparative Law, Vol. 14, nº 3 (2010), p. 4, available at: http://wwwejcl.org. (visitado el 10 de abril de 2020).

${ }^{37}$ Sobre los derechos que pueden invocar las empresas, véase, entre otros, VAN DEN MUIJSENBERGH and REZAI, Loc. cit., pp. 49 y ss.

${ }^{38}$ Sobre este aspecto, véase, en particular, KU, Julian G., "The Limits of Corporate Rights under International Law", Chicago Journal of International Law, Vol. 12, no 2 (2012), pp. 746-747.

${ }^{39}$ Véase, USHAKOVA, “El caso Yukos...”, pp. 135-142; VAN DEN MUIJSENBERGH and REZAI, Loc. cit., pp. 60-68.

${ }^{40}$ En mayo de 2002, según los datos proporcionados por Yukos Universal Limited en su reclamación, Yukos se convirtió en la primera compañía rusa incluida en el ranking de las diez compañías más importantes en el ámbito del petróleo y el gas. Y, en el año siguiente, tras su fusión con Sibneft, pasó a ser la cuarta compañía petrolera más cotizada en el mundo, después de BP, Exxon y Shell. Párr. 46 de la Decisión
} 
El 23 de abril de 2004, Yukos interpuso una reclamación ante el TEDH ${ }^{41}$. En este sentido, el 26 de diciembre de 2007, el Gobierno ruso alegó la falta de competencia ratione personae del TEDH, en base al art. 35.3 del CEDH.

En su decisión sobre la admisibilidad, el Tribunal se pronunció al respecto ${ }^{42}$. A diferencia de su jurisprudencia anterior, tuvo que reconocer que la compañía no estaba bajo el procedimiento concursal en el momento de interposición de la reclamación y, por tanto, la reclamación se había interpuesto correctamente ${ }^{43}$. En cambio, en sus pronunciamientos en los casos similares, el TEDH más bien tenía que partir del hecho de que la empresa había dejado de existir y los altos directivos o accionistas interponían la demanda a favor de la empresa. En este sentido, hubo que desarrollar una interpretación del requisito del art. 34 referente a la condición de "víctima"44.

Además, se consideró la dimensión moral del asunto. De este modo, aunque la existencia de la "víctima de violación" fuese una condición indispensable para poner en marcha el mecanismo ante el TEDH, tal existencia no debería interpretarse de manera rígida, mecánica e inflexible. En conexión con este argumento, se resaltó el papel interpretativo del Tribunal, según el cual no solo tiene que resolver los casos, sino también elucidar, salvaguardar y desarrollar las normas del Convenio, contribuyendo a su cumplimiento por los Estados partes.

Por último, el Tribunal observó que las violaciones del Convenio, alegadas por la compañía, versaban sobre los procedimientos tributarios que conducían al fin de la misma como persona jurídica. En estas circunstancias, la exclusión de la demanda de Yukos sería contraria a la esencia del derecho individual de una persona jurídica, y animaría a los gobiernos a atentar contra las posibilidades de las empresas de reclamar en el momento en que gocen de su personalidad jurídica.

La demanda se presentó en 2004, y la sentencia estimatoria se dictó en 2011, reconociendo parcialmente la violación del art. 6 y del art. 1 del Protocolo ${ }^{\circ} 1$. Pasados dos años, en virtud del art. 41, el Tribunal también acordó una satisfacción equitativa en

provisional sobre la competencia y admisibilidad, de 30 de noviembre de 2009, PCA AA227, Yukos Universal Limited (Isle of Man) c. Federación Rusa, accesible en: http://ita.law.uvic.ca/documents/.

${ }^{41}$ En su demanda, Yukos se apoyó en los siguientes artículos del Convenio: 6, 1, 13, 14, 18 y 7, así como en el art. 1 del Protocolo $n^{\circ} 1$. De conformidad con el art. 41, la compañía reclamó 81 mil millones de euros y 29, 577, 848 euros de interese diarios por daños pecuniarios, "no menos de 100, 000 euros" de daños pecuniarios y 171, 444.60 euros en concepto de costes y gastos.

Además, los dirigentes de Yukos, M. Jodorkovskiy, P. Levedev y V. Aleksanyan interpusieron las demandas individuales contra Rusia ante el TEDH por violación de sus derechos humanos. Véase, respectivamente, TEDH, n 5829/04, Khodorkovskiy c. Federación Rusa, Sentencia de 31 de mayo de 2011; TEDH, n 4493/04, Levedev c. Federación Rusa, Sentencia de 22 de enero de 2008, y TEDH, no 46468/06, Aleksanyan c. Federación Rusa, Sentencia de 22 de diciembre de 2008.

42 Párrs. 439 a 444 de la Decisión sobre la admisibilidad de 29 de enero de 2009, TEDH, nº 14902/04, OAO Neftyanaya Kompaniya Yukos c. Federación Rusa, en: http://cmiskp.echr.coeint/.

${ }^{43}$ Ver los asuntos ECtHR, no 49429/99 Capital Bank AD c. Bulgaria, Sentencia de 24 de noviembre de 2005, y ECtHR, no 29010/95 Credit and Industrial Bank c. República Checa, Sentencia de 21 de octubre de 2003. En ambos casos, el Tribunal reconoció que actuaron a favor de los bancos las personas interesadas, tales como el cuerpo directivo o los accionistas.

${ }^{44}$ Véase EMBERLAND, Marius, "The Corporate Veil in the Case Law of the European Court of Human Rights”, Zä̈RV, 63 (2003), 945-969, pp. 946-947. 
la cuantía de 1,8 mil millones (en la demanda inicial, esta suma ascendía a 81 mil millones de euros).

Junto con los derechos a un proceso equitativo (art. 6) ${ }^{45}$ y a la propiedad (art. 1 del Protocolo $\mathrm{n}^{\circ}$ 1), cuya violación se constató en el asunto Yukos c. Rusia, las empresas han venido alegando la violación de algunos otros, cuya admisibilidad, interpretación y protección resultan bastante más contradictorias. Tales son los derechos a la libertad de expresión (art. 10), o al respeto de la vida privada y familiar (art. 8). La dificultad reside no solo en la naturaleza corporativa del sujeto, sino también en la aplicación de la doctrina del margen de apreciación amplio ${ }^{46}$. Tradicionalmente, el Tribunal concede un margen de apreciación amplio a los Estados para restringir estos derechos.

Así, el art. 10 lo han alegado algunas empresas editoriales. Por ejemplo, en el primer asunto promovido por una persona de carácter corporativo Sunday Time c. el R.U., el Tribunal constató la violación del art. 10 por once votos contra nueve ${ }^{47}$. Asimismo, en la reclamación de la compañía de telecomunicaciones Autronic AG c. Suiza, el TEDH reconoció la vulneración del mismo artículo, reafirmando el derecho de una compañía a recibir la información de manera transfronteriza para obtener el beneficio económico ${ }^{48}$.

Más recientemente, el TEDH se ha pronunciado sobre la aplicación del art. 10 en el caso de una página de noticias de Internet. El asunto Delfi AS c. Estonia ha resultado pionero en el análisis de la responsabilidad de la compañía por los comentarios ofensivos,

\footnotetext{
${ }^{45}$ Cabe destacar que el derecho a un proceso equitativo es el que más se invoca ante el Tribunal. Según los datos estadísticos, en cerca del 30\% de las sentencias del Tribunas dictadas en 2017, se constató la violación del art. 6 del Convenio. ECHR, The ECHR in Facts \& Figures 2017, March 2018, p. 7. Esta cifra asciende al $40 \%$ en el período entre 1959 y 2017. ECHR, Overview 1959-2017, March 2018, p. 5.

Según The ECHR in Facts \& Figures 2019, la cuarta parte de todas las violaciones contabilizadas en el año 2019 se refería al art. 6. Una información más detallada se halla disponible en: https://www.echr.coe.int/Documents/Facts_Figures_2019_ENG.pdf (consultado el 10 de abril de 2020).

Sobre las particularidades de aplicación del art. 6 a las empresas, véase, entre otros, VAN KEMPEN, Loc. cit., pp. 14-16.

${ }^{46}$ The Court first explained the margin of appreciation in ECtHR, $\mathrm{n}^{\circ}$ 5493/72, Handyside v the U.K., Judgment of 7 December 1976. In that case, the Court had to consider whether a conviction for possessing an obscene article could be justified under Article 10(2) as a limitation upon freedom of expression that was necessary for the protection of morals. The Court noted: "By reason of their direct and continuous contact with the vital forces of their countries, state authorities are in principle in a better position than the international judge to give an opinion on the exact content of those requirements [of morals] as well as on the 'necessity' of a 'restriction' or 'penalty' intended to meet them ...". ECtHR, $\mathrm{n}^{\circ}$ 5493/72, Handyside $v$ the U.K., Judgment of 7 December 1976, para. 48. Véase más información en "Margin of Appreciation", ECHR Reform, April 2012.

El término "margen de apreciación" se refiere al espacio de maniobra que los órganos de Estrasburgo desean proporcionar a las autoridades nacionales en su cumplimiento de las obligaciones del CEDH. En particular, el TEDH ha venido aplicando dicha doctrina a los artículos de la Convención que contienen las cláusulas de "acomodación" o de "limitación", esto es, arts. 8-11. Véase: "The margin of appreciation" en: https://www.coe.int/t/dghl/cooperation/lisbonnetwork/themis/echr/paper2 en.aspitself (visitado el 2 de abril de 2020), y KAVANAUGH, Kathleen A., "Policing the Margins: Rights Protection and the European Court of Human Rights", European Human Rights Law Review, n 4(2006), p. 425.

En virtud del Protocolo $\mathrm{n}^{\circ} 16$ (ETS $\left.\mathrm{n}^{\circ} 213\right)$, en vigor desde el 1 de agosto de 2018, la referencia a la doctrina del margen de apreciación, desarrollada en la jurisprudencia del TEDH, se introduce en el Preámbulo del Convenio.

${ }^{47}$ ECtHR, $n^{\circ} 6538 / 74$, Judgment of 26 April 1979.

${ }^{48}$ ECtHR, $n^{\circ} 12726 / 87$, Judgment of 22 May 1990.
} 
generalmente anónimos, publicados por sus lectores ${ }^{49}$. En este supuesto, el Tribunal decidió por unanimidad que las autoridades de Estonia habían impuesto restricciones justificadas y proporcionadas a la libertad de expresión del portal de noticias y, por lo tanto, no había violación del art. 10.

En cuanto al art. 8, en ocasiones, el Tribunal ha equiparado el término "domicilio privado" con la oficina de una empresa. Así ocurrió en el asunto Société Colas Est y otros c. Francia $^{50}$. En este supuesto, las dependencias de la compañía fueron intervenidas por los investigadores del Gobierno francés, sin solicitar el permiso previamente y sin la autorización judicial, al parecer, una omisión amparada por la legislación entonces en vigor en Francia. Del mismo modo, mutatis mutandis, en el asunto Niemietz $c$. Alemania $^{51}$, el Tribunal se inspiró en los valores del pragmatismo y la efectividad, y aplicó el art. 8 al supuesto relacionado con la protección de la privacidad de un despacho de abogados. En su Sentencia final en el asunto Société Colas Est, con fundamento en la interpretación dinámica del CEDH, el Tribunal determinó que había llegado el momento de aplicar, en ciertas circunstancias, la garantía del derecho contenido en el art. 8 también a la sede registrada de la compañía y de sus dependencias ${ }^{52}$.

Por último, algunos de los derechos del Convenio, como, por ejemplo, el derecho a la vida (art. 2) ${ }^{53}$ o la prohibición de la tortura (art. 3), son claramente difíciles de alegar en el caso de las empresas. Tal interpretación sería inviable, ya que, dado el carácter casi absoluto de los derechos mencionados, el Estado se privaría de cualquier posibilidad de llevar a cabo un registro o reaccionar en el plano fiscal. No obstante, como se ha demostrado, entre otros, en el caso Yukos, las autoridades estatales pueden contribuir al fin de la existencia de la empresa, y, como consecuencia de estos actos, alegar la inadmisibilidad debido a la ausencia de la "víctima".

\section{La responsabilidad por violación de los derechos.}

En cuanto al segundo elemento de la subjetividad internacional, esto es, la capacidad de responder por la violación de los derechos, solo los Estados pueden ser responsables en el sistema del Consejo de Europa. Cabe recordar que, desde los años 70, se han llevado a cabo intentos de incorporar la Comunidad Europea (y, posteriormente, la Unión Europea) como parte del $\mathrm{CEDH}^{54}$. En la última ocasión, se realizaron las reformas pertinentes tanto

\footnotetext{
49 ECtHR, Delfi AS v. Estonia, no 64569/09, Judgment of 10 October 2013. Sobre este caso, véase el comentario de SUSI, Mart, in "International decisions", American Journal of International Law, Vol. 108 (2014), pp. 295-302.

${ }^{50}$ ECtHR, no 37971/97, Judgment of 16 April 2002.

${ }^{51}$ ECtHR, no 13710/88, Judgment of 16 December 1992.

52 "Building on its dynamic interpretation of the Convention, the Court considers that the time has come to hold that in certain circumstances the rights guaranteed by Article 8 of the Convention may be construed as including the right to respect for a company's registered office, branches or others business premises", ECtHR, no 37971/97, Judgment of 16 April 2002, para 41.

${ }^{53}$ VAN DEN MUIJSENBERGH and REZAI, Loc. cit., pp. 59-60.

54 Véase Dictamen 2/94 del Tribunal de Justicia, de 28 de marzo de 1996, sobre la adhesión de la Comunidad al Convenio para la Protección de los Derechos Humanos y de las Libertades Fundamentales,
} 
de los Tratados Fundacionales de la Unión, como del Convenio. Así, el art. 6.2 del Tratado de la Unión Europea (TUE) ${ }^{55}$ introdujo el imperativo jurídico de formar parte del Convenio, y el art. 59.2 del CEDH, añadido por el Protocolo $n^{\circ} 14^{56}$, permitía explícitamente tal adhesión. Sin embargo, en su Dictamen de 2014, el Tribunal de Justicia de la Unión Europea volvió a alegar la imposibilidad de dicha acción, debido a la incompatibilidad con el ordenamiento jurídico de la UE y al hecho de que no es un Estado.

A finales del año 2019, se reanudó el proceso de negociaciones entre las dos OO.II ${ }^{57}$. Por razones bien conocidas, la adhesión de la UE al CEDH sigue siendo una de las prioridades del Consejo de Europa ${ }^{58}$. En primer lugar, permite a la Unión formar parte del sistema de protección de los derechos humanos más desarrollado y avanzado. Junto con la protección que asegura el Tribunal de Justicia de la Unión Europea, contaría con el control externo del Tribunal Europeo de Derechos Humanos. En segundo lugar, y como consecuencia de lo anterior, aseguraría la coherencia entre los planteamientos en la materia de ambos órganos jurisdiccionales. Por último, la adhesión de la UE contribuiría a su mayor credibilidad, dado que, en sus relaciones con terceros Estados, insiste en la importancia de respetar el Convenio Europeo.

En todo caso, aunque prospere esta nueva iniciativa, la responsabilidad por violación de los derechos humanos se extendería a otro sujeto reconocido del Derecho internacional, esto es, una OI. Este hecho, por sí solo, no abriría la puerta a la extensión de la responsabilidad a otros actores. Mientras tanto, los Estados permanecen como únicos sujetos con legitimación pasiva.

Sin embargo, consciente del papel cada vez más importante de las empresas, el Consejo de Ministros emprendió acciones para abordar el problema de las empresas y la protección de los derechos humanos. El primer paso se hizo en 2010, cuando la Asamblea Parlamentaria del Consejo de Europa adoptó dos resoluciones sobre el tema (Resolución $\mathrm{n}^{\mathrm{o}} 1757$ y la Recomendación $\mathrm{n}^{\mathrm{o}}$ 1936) ${ }^{59}$. En 2011, el Comité Directivo de Derechos Humanos del Consejo de Ministros publicó un estudio preliminar sobre los estándares y aspectos relevantes de la responsabilidad social corporativa en materia de derechos humanos ${ }^{60}$. Tras esta publicación, el Consejo de Ministros encomendó a su Comité la elaboración de una declaración de apoyo a los Principios Rectores de la ONU ${ }^{61}$

\footnotetext{
y el Dictamen 2/13 del Tribunal de Justicia, de 18 de diciembre de 2014, sobre la adhesión de la UE al Convenio.

${ }^{55}$ El Tratado de Lisboa, en vigor desde el 1 de diciembre de 2009, introdujo este imperativo en el art. 6.2 del TUE. Véase el Texto refundido del TUE en DO L 202, de 7 de junio de 2016.

${ }^{56}$ Protocolo $\mathrm{n}^{\mathrm{o}}$ 14, de 3 de mayo de 2002, en vigor desde el 1 de junio de 2010.

57 Véase la información más detallada en: https://www.coe.int/en/web/human-rights-intergovernmentalcooperation/accession-of-the-european-union-to-the-european-convention-on-human-rights (consultado el 20 de abril de 2020).

58 Ibid.

${ }^{59}$ O'BRIEN, Claire Methven, Business and Human Rights. A handbook for legal practitioners, November 2018, Council of Europe, Strasbourg, 2018, p. 168.

${ }^{60}$ Citado por O'BRIEN, op. cit. Ibid.

${ }^{61} \mathrm{UN}$, Principios Rectores sobre las empresas y los derechos humanos: puesta en práctica del marco de las Naciones Unidas para "proteger, respetar y remediar", Anexo al Informe del Representante Especial del Secretario General de la ONU para la cuestión de los derechos humanos y las empresas transnacionales
} 
incluyendo la guía de buenas prácticas y los desafíos de implementación de los Principios en Europa.

En este orden de ideas, el Comité de Ministros aprobó la Declaración sobre los Principios Rectores de la ONU, de 2014 ${ }^{62}$, y la Recomendación sobre los derechos humanos y las empresas, de $2016^{63}$, instando a los Estados miembros del Consejo de Europa a asegurar su responsabilidad en el plano nacional. Pese a que la Recomendación se fundamenta en una serie de tratados del Consejo, en particular el CEDH y las Cartas Sociales ${ }^{64}$, su fuente de inspiración principal son los Principios Rectores de la ONU. De hecho, el propósito central de este instrumento es la implementación efectiva de los Principios en el ámbito europeo como un fundamento consensuado a nivel global sobre las empresas y los derechos humanos, y la revisión y evaluación de la legislación y la práctica nacionales al respecto en unos plazos regulares.

Con todo, el Consejo de Europa opta por continuar en la línea de actuación en relación con la responsabilidad de las empresas de otros órganos y organismos internacionales y regionales, consistente en la adopción de instrumentos de soft law ${ }^{65}$, descartando un instrumento vinculante. Este proceso se ha descrito como "densificación normativa ... a través de la emergencia... de una importante «malla» de instrumentos, primero de ámbito internacional y luego también nacionales, que comparten dos rasgos básicos: su propósito de introducir pautas ordenadoras del comportamiento socialmente responsable de dichas empresas y el recurso para su diseño de dos conceptos clave, no utilizados antes en este ámbito: los de debida diligencia, como criterio de definición de esas pautas, y de esfera de influencia, como elemento delimitador de su radio de aplicación" ${ }^{66}$.

Entre los antecedentes, muchos de los cuales se han revisado recientemente a la luz de los Principios Rectores de la ONU, cabe mencionar: las Normas sobre las responsabilidades de las empresas transnacionales y otras empresas comerciales en la esfera de los derechos humanos, elaboradas por la Comisión de Derechos Humanos de la

\footnotetext{
y otras empresas, John Ruggie, 21 de marzo de 2011, Consejo de Derechos Humanos, 17. ${ }^{\circ}$ período de sesiones, UN Doc. A/HRC/17/31. El Consejo de Derechos Humanos hizo suyos los Principios Rectores en su Resolución 17/4, de 16 de junio de 2011.

${ }^{62}$ Declaración del Consejo de Ministros sobre los Principios Rectores de la ONU, aprobada el 16 de abril de 2014 en la reunión no 1197 de los Delegados de Ministros.

${ }^{63}$ Recommendation CM/Rec (2016)3 of the Committee of Ministers to Member States, Human Rights and Business, adopted on 2 March 2016, Council of Europe, Strasburg 2016, disponible en: https://edoc.coe.int/en/fundamental-freedoms/7302-human-rights-and-business-recommendationcmrec20163-of-the-committee-of-ministers-to-member-states.html (consultado el 3 de abril de 2020). ${ }^{64}$ Carta Social Europea, de 1961 (ETS no 35 ) y Carta Social Europea (Revisada), de 1996 (ETS no 163). ${ }^{65}$ VALDÉS DAL-RÉ, Fernando, «Soft law, Derecho del trabajo y orden económico globalizado», Relaciones Laborales, $\mathrm{n}^{\circ} 4$ (2005), p. 5; MONEREO PÉREZ, José Luis, "La racionalización jurídica de las relaciones laborales y la emergencia de nuevas fuentes reguladoras en el orden internacional", Lex Social. Revista Jurídica de los Derechos Sociales, Vol. 8, n 1 (2018), p. 29; LANTARÓN BARQUín, David,“¿Hacia un sistema 'cosmopolita' de fuentes del Derecho del Trabajo? La empresa multinacional como detonante del cambio", Trabajo y derecho: nueva revista de actualidad y relaciones laborales, $\mathrm{n}^{\circ} 10$ Extra (2019), p. 12.

${ }^{66}$ SANGUINETI RAYMOND, Wilfredo, "Los límites del poder privado de las empresas multinacionales", Trabajo y derecho: nueva revista de actualidad y relaciones laborales, ${ }^{\circ} 10$ Extra (2019), p. 7.
} 
ONU en 2003 ${ }^{67}$; las Líneas Directrices de la Organización para la Cooperación y el Desarrollo Económico (OCDE) sobre las empresas multinacionales, actualizadas en 201168; la Declaración Tripartita de Principios sobre las Empresas Multinacionales y la Política Social de la Organización Internacional del Trabajo (OIT), revisada en $2017^{69}$, y el Pacto Global de la ONU, de $2000^{70}$, el instrumento sobre la responsabilidad social corporativa más relevante en el plano internacional universal.

Volviendo al planteamiento del sistema del Consejo de Europa, la Recomendación busca ofrecer una guía a los Estados miembros para implementar los Principios Rectores de la ONU. Como se indica en el Memorando explicativo, no todas las disposiciones de los Principios están explícitamente reflejadas, sino tan solo aquellas con que el Comité de Ministros pretende colmar las lagunas en el plano regional europeo ${ }^{71}$. No obstante, debe entenderse que todas las disposiciones de los Principios tienen que implementarse.

Al igual que se observa en relación con la legitimación activa de las empresas, la Recomendación acoge un concepto amplio, esto es, se refiere a todo tipo de empresas, tanto multinacionales como otras, con independencia de su tamaño, sector, propiedad o estructura. Incluso el carácter estatal de la compañía no es excluyente en este caso.

Los Estados, como únicos sujetos legitimados, se comprometen a asegurar que su legislación nacional se revise de conformidad con la Recomendación, así como a compartir las buenas prácticas (párrs. 1 y 3). La supervisión de la implementación está prevista no más tarde que cinco años después de la adopción, y concebida como un proceso abierto, con participación de todos los interlocutores relevantes, en particular, de los representantes de los empresarios, las empresas, los sindicatos, las instituciones nacionales de derechos humanos (INDS) y las ONGs, que puedan completar de manera constructiva los cuestionarios correspondientes de los Estados y contribuir al proceso de seguimiento.

A los efectos de la implementación y supervisión, cada uno de los tres pilares de los Principios Rectores de la ONU “proteger, respetar y remediar" posee un valor equivalente, aunque con un acento especial en el tercero.

En cuanto al primer pilar, la Recomendación desarrolla el deber de los Estados de proteger los derechos humanos con especial referencia a los instrumentos del Consejo de Europa: el CEDH, tal y como se interpreta y se aplica por el TEDH, y la Carta Social Revisada, a

\footnotetext{
${ }^{67} \mathrm{UN}$, Normas sobre las responsabilidades de las empresas transnacionales y otras empresas comerciales en la esfera de los derechos humanos, Resolución 2003/16, de la Comisión de Derechos Humanos, de 13 de agosto de 2003, UN Doc. E/CN.4/Sub.2/2003/12/Rev.2.

68 OCDE, Líneas Directrices de la OCDE para Empresas Multinacionales, OECD Publishing, 2013, disponible en: http://dx.doi.org/10.1787/9789264202436-es (consultado el 2 de abril de 2020).

${ }^{69}$ OIT, Declaración Tripartita de Principios sobre las Empresas Multinacionales y la Política Social de la Organización Internacional del Trabajo, de 1977, 5ª Ed., Oficina Internacional del Trabajo, Ginebra 2017. ${ }^{70}$ UN, Pacto Global de las Naciones Unidas, disponible en: https://www.unglobalcompact.org/Languages/spanish/index.html (consultado el 3 de abril de 2020).

${ }^{71}$ COUNCIL OF EUROPE, Explanatory Memorandum to Recommendation CM/Rec (2016)3 of Committee of Ministers to member States on human rights and business, CM (2016)18-addfinal, 2 March 2016, para. 5 .
} 
la luz de las conclusiones y decisiones del Comité Europeo de Derechos Sociales $(\mathrm{CEDS})^{72}$.

El segundo pilar de los Principios se refiere al papel de las empresas como entes especializados de la sociedad, con funciones determinadas cuyo ejercicio requiere el respeto de las leyes aplicables y de los derechos humanos. Se trata de la responsabilidad corporativa, que significa que las empresas deben evitar la vulneración de los derechos humanos y prevenir los efectos adversos en este plano debido a su actividad. De este modo, la responsabilidad de las empresas de respetar los derechos humanos es una norma global de conducta esperada de estos actores, que se plantea independientemente de la capacidad o la voluntad de los Estados de cumplir sus propias obligaciones en la materia $^{73}$. Dicha responsabilidad implica el cumplimiento de las leyes y reglamentos nacionales aplicables en el territorio de cada Estado, incluidas las leyes que establecen la obligación de due diligence (debida diligencia) para las empresas. De los Principios Rectores 17-21 se deduce que la debida diligencia de las empresas en materia de derechos humanos tendría que incluir cuatro componentes: la evaluación del impacto real y potencial de sus actividades sobre los derechos humanos; la integración de las conclusiones y adopción de medidas al respecto; el seguimiento de las respuestas, y la decisión sobre la forma en que se abordan los efectos ${ }^{74}$.

Una de las primeras propuestas en este sentido se aprobó en Francia. La Ley 2017-399, de 27 de marzo de 2017, contempla el deber de vigilancia para las empresas ${ }^{75}$. Se aplica a las empresas más grandes, y les obliga a analizar y abordar los impactos adversos de sus actividades en las personas y en el medioambiente y a publicar anualmente planes de vigilancia, que incluyen los impactos relacionados con sus propias actividades, con aquellas de las compañías bajo su control directo y los de proveedores y subcontratas, con quienes tengan una relación comercial regular.

Siguiendo el ejemplo de Francia, otros Estados han promovido proyectos legislativos similares $^{76}$. Así, en Suiza, se han entregado al gobierno las firmas necesarias para celebrar un referéndum en relación con la debida diligencia en materia de derechos humanos. Del mismo modo, el Parlamento holandés ha aprobado la propuesta de ley sobre Debida Diligencia en relación con el Trabajo Infantil (Child Labour Due Diligence Law o Wet Zorgplicht Kinderarbeid). La Ley requiere que las empresas identifiquen si existe trabajo

\footnotetext{
72 COUNCIL OF EUROPE, Explanatory Memorandum, papa. 9.

${ }^{73}$ Principio 11 de los Principios Rectores; NINO, Michele, "El análisis del land grabbing a la luz de la norma internacional de la soberanía territorial”, REDI, Vol. 71, nº 1 (2019), p. 218 y ss.

${ }^{74}$ NINO, Loc. cit., p. 220.

75 Véase LOI no 2017-399 du 27 mars 2017 relative au devoir de vigilance des sociétés mères et des entreprises donneuses d'ordre, Journal Officiel de la République Française, 28 mars 2017. Al respecto, véase la contribución del profesor AUVERGNON, Philippe al presente número de la Revista Lex Social.

76 Véase más información en el Observatorio de Responsabilidad Social Corporativa, disponible en: https://observatoriorsc.org/francia-aprueba-la-ley-deber-vigilancia-las-empresas/ (consultado el 10 de abril de 2020). Sobre las leyes emergentes relativas a la debida diligencia, véase O'BRIEN, op. cit, pp. 94-95.

BUENO, Nicolas, "Multinationas Enterprases and Labour Rights: Concepts and Implementation", in BELLACE, Janice and TER HAAR, Beryl (Eds.), Research Handbook on Labour, Business and Human Rights Law, Edward Elgar Publishing, Cheltenham, Northampton, 2019, pp. 421-438.
} 
infantil a lo largo de sus cadenas de suministro y que, en caso afirmativo, desarrollen un plan para evitarlo.

Al respecto, el art. 15 (b) del Estatuto del Consejo de Europa prevé la posibilidad de adoptar las recomendaciones del Comité de Ministros a los Estados miembros, pero no a los sujetos privados. Es la razón por el que se elabora este instrumento en forma de recomendación a los Estados sobre las medidas de la responsabilidad corporativa en materia de derechos humanos.

El tercer pilar insiste en que los derechos y obligaciones tienen que ir acompañados del acceso a los recursos apropiados y efectivos. En particular, se pone énfasis sobre el acceso a la justicia, teniendo en cuenta toda la experiencia del TEDH, el Comité de los Derechos Sociales y otros órganos del Consejo. El Anexo a la Recomendación detalla el acceso a los mecanismos judiciales y no judiciales. Entre los judiciales se distingue entre la responsabilidad civil por abusos de los derechos humanos por parte de las empresas ${ }^{77}$, la responsabilidad penal o equivalente ${ }^{78}$ y las medidas administrativas ${ }^{79}$.

Por último, el Anexo a la Recomendación se refiere a la protección adicional de algunos colectivos, en concreto: los trabajadores ${ }^{80}$, los niños ${ }^{81}$, los pueblos indígenas ${ }^{82}$ y los defensores de los derechos humanos ${ }^{83}$.

En el proceso de implementación, la no discriminación se perfila como un principio general, con apoyo en el art. 14 del CEDH y la práctica del TEDH. Del mismo modo, se toman en consideración los estándares relevantes europeos y universales. El mensaje de los Estados miembros tiene que ser coherente e inequívoco, para que las empresas adopten la actitud correspondiente al respecto.

Con anterioridad a la adopción de la Recomendación de 2016, el Comité de Ministros contemplaba la necesidad de previsión de los planes de acción nacionales para la implementación de los Principios Rectores de la ONU en su Declaración de $2014^{84}$. La Recomendación reitera este llamamiento ${ }^{85}$. Se sugiere a los Estados miembros del Consejo de Europa que creen las condiciones favorables para que las empresas respeten los derechos humanos y eliminen los obstáculos para la responsabilidad empresarial en el supuesto de su violación ${ }^{86}$. Con este fin, los Estados que ya cuentan con planes de acción deben evaluar sistemáticamente los avances al respecto e identificar lagunas e impedimentos. La supervisión tiene que llevarse a cabo teniendo en cuenta no solo las indicaciones del Consejo de Europa y la ONU, sino también de otras organizaciones y organismos pertinentes, por ejemplo, de la OIT.

\footnotetext{
${ }_{77}$ Párrs. 32-43; COUNCIL OF EUROPE, Explanatory Memorandum, paras. 55-66.

${ }^{78}$ Parrs. 44-46; COUNCIL OF EUROPE, Explanatory Memorandum, paras. 67-76.

${ }^{79}$ Párrs. 47-48; COUNCIL OF EUROPE, Explanatory Memorandum, para. 77.

${ }^{80}$ Parrs. 58-60; COUNCIL OF EUROPE, Explanatory Memorandum, paras. 86-88.

${ }^{81}$ Parrs. 61-64; COUNCIL OF EUROPE, Explanatory Memorandum, paras. 89-92.

${ }^{82}$ Párrs. 65-68; COUNCIL OF EUROPE, Explanatory Memorandum, paras. 93-94.

${ }^{83}$ Párrs. 69-70; COUNCIL OF EUROPE, Explanatory Memorandum, paras. 95-97.

${ }^{84}$ Párr. 10 (b).

${ }^{85}$ Párr. 4 de la Recomendación y párrs. 10-12 del Anexo a la Recomendación.

86 Párr. 18 del Anexo a la Recomendación.
} 
Según los datos disponibles en 2018, cerca de 20 Estados del Consejo de Europa contaban con este instrumento en la materia de empresas y derechos humanos, entre otros: Alemania, Bélgica, la República Checa, España, Dinamarca, Finlandia, Francia, Italia, Países Bajos y Polonia ${ }^{87}$.

En España, un Plan de Acción se aprobó en 2017, aunque, entre sus fundamentos jurídicos, no se menciona la Recomendación del Consejo de Ministros de 2016. Más bien, se refleja el compromiso con los Principios Rectores de la ONU, cuyos principios de 8 a 10 se refrenen a este particular. Concretamente, y para asegurar la máxima publicidad, se adoptó la Resolución de 1 de septiembre de 2017, de la Secretaría de Estado de Asuntos Exteriores, por la que publicó el Plan de Acción Nacional de Empresas y Derechos Humanos $^{88}$. Tal y como aconseja la Recomendación, se trataba de aplicar los Principios Rectores de la ONU, detectar los antecedentes y el contexto, establecer los ámbitos de actuación y medidas, y llevar a cabo el seguimiento y la actualización.

Cabe señalar que, en el Plan Nacional, se habla de la aprobación por el Congreso de Deputados de la Proposición de Ley sobre Responsabilidad Social Corporativa y Derechos Humanos, de 4 de abril de 2013. Por otro lado, se menciona la Estrategia Española de Responsabilidad Social de las Empresas, aprobada por el Consejo de Ministros, el 24 de octubre de 2014. En la Estrategia, el concepto de responsabilidad se considera de manera amplia como impacto de las empresas en las sociedades.

El Plan Nacional desarrolla y especifica los compromisos de España en torno a dos pilares: "Proteger" y "Remediar": Pilar I: El deber del Estado de proteger los derechos humanos ${ }^{89}$ y Pilar III Acceso a mecanismos de reparación ${ }^{90}$. A su vez, cada uno de los pilares distingue entre los principios fundacionales y los principios operacionales, incorporando los correspondientes principios rectores de la ONU.

Como puede observarse, falta el Pilar II relativo a la responsabilidad de las empresas de respetar los derechos humanos. Parece que, dentro del Pilar I, el Estado asume la responsabilidad de proteger frente a las violaciones y abusos cometidos por terceros.

\section{Las manifestaciones de la responsabilidad en la práctica del TEDH.}

Una vez más, hay que subrayar que el Estado es el único responsable por violación de los derechos humanos protegidos por el CEDH. Toda reclamación contra las personas físicas o jurídicas es sistemáticamente rechazada ratione personae, como incompatible con los requisitos de admisibilidad ${ }^{91}$. Como contrapartida, la soberanía del Estado en su territorio

\footnotetext{
${ }^{87}$ O’BRIEN, op. cit., p. 60.

${ }^{88}$ Resolución de 1 de septiembre de 2017, de la Secretaría de Estado de Asuntos Exteriores, por la que publica el Plan de Acción Nacional de Empresas y Derechos Humanos, B.O.E. núm. 222, de 14 de septiembre de 2017.

${ }^{89}$ Véase el apartado "B” del Plan, B.O.E. núm. 222, de 14 de septiembre. Sec. III., Pág. 90388 y ss.

${ }^{90}$ Véase el apartado “C” del Plan, B.O.E. núm. 222, de 14 de septiembre. Sec. III., Pág. 90397 y ss.

91 POLAKIEWICZ, Jörg, Corporate Responsibility to Respect Human Rights: Challenges and Opportunities for Europe and Japan, Nagoya University, publicado el 1 de octubre de 2012, p. 8.,
} 
y el debido respeto a la jurisdicción nacional se ven reforzados en el requisito de agotamiento de los recursos internos. En palabras de Gosalbo Bono, esta norma posee un carácter mixto $^{92}$. Por un lado, actúa como condición de admisibilidad de una demanda o una regla procesal que asegura un cierto equilibrio entre la soberanía del Estado demandado y las exigencias superiores del Derecho internacional (art. $35 \mathrm{CEDH}$ ). Por otro lado, se concibe como un instrumento que garantiza el cumplimiento de derechos y obligaciones sustantivos, entre otros, el derecho de toda persona a un recurso efectivo en caso de violación de sus derechos y libertades (art. $13 \mathrm{CEDH}$ ).

A pesar de que el CEDH carece de efecto directo sobre los terceros, implica la responsabilidad positiva del Estado para proteger los derechos humanos y asegurar la reparación que resulta de su violación por los sujetos privados. La responsabilidad deriva de la obligación positiva del Estado, una técnica desarrollada por el $\mathrm{TEDH}^{93}$. De este modo, el Tribunal Europeo se considera como la primera instancia jurisdiccional internacional que ha reconocido la posibilidad de que los derechos convencionales generen no solo obligaciones negativas sino también obligaciones positivas a cargo del Estado $^{94}$. Las obligaciones positivas del Estado se conectan con el objetivo 1 de los Principios Rectores de la ONU, y comprenden el deber de adoptar "medidas razonables y apropiadas" 95 para proteger los derechos humanos.

El TEDH desarrolla la doctrina, en particular, en el asunto $X$ and $Y$ c. Holanda ${ }^{96}$, al afirmar que las obligaciones del Estado no solo se limitan a abstenerse de interferir en los derechos individuales, sino también implican adoptar medidas positivas para la protección efectiva de los mismos, incluso en el ámbito de relaciones entre las personas privadas. La jurisprudencia relativa a la responsabilidad positiva en el contexto del art. 8 CEDH se resume en el asunto Moldovan y otros c. Romania ${ }^{97}$.

En concreto, el Tribunal sostiene que, aunque este artículo está concebido para proteger a los individuos contra la intervención arbitraria de los poderes públicos, el precepto no se limita a prevenir tal interferencia. El compromiso inicial de abstenerse debe completarse con la obligación positiva, que puede implicar la adopción de medidas destinadas a respetar los derechos, incluso en el ámbito de relaciones individuales ${ }^{98}$. Además, la aquiescencia o connivencia de las autoridades de un Estado contratante en los actos de los particulares que violen los derechos del Convenio de otras personas dentro

\footnotetext{
disponible en: https://www.business-humanrights.org/en/pdf-corporate-responsibility-to-respect-humanrights-challenges-and-opportunities-for-europe-and-japan (visitado el 5 de julio de 2018).

${ }_{92}$ GOSALBO BONO, Ricardo, "Consideraciones en torno a la distinción entre el fondo y la forma en el Derecho internacional (público y privado)", REDI, Vol. 71, nº 1(2019), p. 33.

${ }^{93}$ CARMONA CUENCA, Encarnación, "Derechos sociales de prestación y obligación positiva del Estado en la jurisprudencia del Tribunal Europeo de Derechos Humanos", Revista de Derecho Político, $\mathrm{n}^{\circ} 100$ (2017), pp. 1216.

${ }^{94}$ CARMONA CUENCA, Loc. cit., p. 1216.

${ }^{95}$ ECtHR, Fadeyeva v. the Russian Federation, $n^{\circ}$ 55273/00, Judgment of 9 June 2005, para 89.

${ }^{96}$ ECtHR, $X$ and $Y$ v. the Netherlands, $\mathrm{n}^{\circ} 8978 / 80$, Judgment of 26 March 1985, para. 23.

${ }^{97}$ ECtHR, Moldovan and Others v. Romania, $\mathrm{n}^{\circ} 41138 / 98$ and 64320/01, Judgment $\mathrm{n}^{\circ} 2$ of 12 July 2005, paras. 93-99.

${ }^{98}$ ECtHR, $X$ and $Y$ v. the Netherlands, $n^{\circ} 8978 / 80$, Judgment of 26 March 1985, para. 23; ECtHR, Moldovan and Others v. Romania, $\mathrm{n}^{\circ} 41138 / 98$ and 64320/01, Judgment $\mathrm{n}^{\circ} 2$ of 12 July 2005, para. 93.
} 
de su jurisdicción pueden comprometer la responsabilidad del Estado ${ }^{99}$. Es más, el Estado puede responder en el supuesto en que sus agentes actúen ultra vires o contra las instrucciones ${ }^{100}$.

La responsabilidad se plantea cuando las repercusiones de los actos afectan directamente a los derechos garantizados por la CEDH. Al respecto, resulta relevante evaluar el compromiso posterior del Estado ${ }^{101}$. El Tribunal no excluye la posibilidad de que la obligación positiva del Estado en virtud del art. 8 se extienda a la efectividad de la investigación criminal.

Tanto en el caso de la obligación positiva del Estado como en el de la injerencia injustificada de los poderes públicos, se trata de alcanzar un equilibrio justo entre los intereses individuales y los de la comunidad en su conjunto. En ambos casos, el Estado posee un cierto margen de apreciación para decidir sobre las medidas necesarias para cumplir con los compromisos en virtud del Convenio ${ }^{102}$. Para lograr el equilibrio necesario, en relación con las obligaciones positivas del art. 8.1, pueden resultar relevantes los objetivos señalados en el art. 8.2 $2^{103}$.

Dichas interpretaciones del TEDH se inspiran en, y se conectan, con la conocida doctrina de la Drittwirkung der Grundrechte, que alude a la eficacia horizontal, o a la incidencia de los derechos fundamentales en las relaciones entre particulares ${ }^{104}$. Sus raíces remiten a la célebre Sentencia del Tribunal Constitucional Federal alemán en el caso Lüth, dictada el 15 de enero de $1958^{105}$. Otros países han desarrollado teorías análogas, tales como la state action doctrine de Estados Unidos de América o la third-party or horizontal effect del Reino Unido, Canadá y Sudáfrica ${ }^{106}$.

Sin duda, la aplicación de esta doctrina por el TEDH ofrece una vía interesante de reflexión sobre una posible responsabilidad de las empresas y las EMN en el sistema del Convenio. Aunque no existe una opinión uniforme al respecto, debido a la complejidad de la doctrina de la Drittwirkung y sus múltiples manifestaciones, algunos jueces han expresado su apoyo a la eficacia horizontal de los derechos. Por ejemplo, el juez

\footnotetext{
${ }^{99}$ ECtHR, Cyprus v. Turkey [GC], no 25781/94, ECHR 2001-IV, para. 81; ECtHR, Moldovan and Others v. Romania, $\mathrm{n}^{\circ} 41138 / 98$ and 64320/01, Judgment $\mathrm{n}^{\circ} 2$ of 12 July 2005, para. 94.

${ }^{100}$ ECtHR, Ireland v. the United Kingdom, $\mathrm{n}^{\circ}$ 5310/71, Judgment of 18 January 1978, para. 159; ECtHR, Moldovan and Others $v$. Romania, $\mathrm{n}^{\circ} 41138 / 98$ and 64320/01, Judgment $\mathrm{n}^{\mathrm{o}} 2$ of 12 July 2005, para. 94.

${ }^{101}$ ECtHR, Ilaşcu and Others v. Moldova and Russia [GC], no. 48787/99, Judgment of 8 July 2004, paras. 317, 382, 384-85 and 393; ECtHR, Moldovan and Others v. Romania, n ${ }^{\circ} 41138 / 98$ and 64320/01, Judgment $\mathrm{n}^{\mathrm{o}} 2$ of 12 July 2005, para. 95.

${ }^{102}$ ECtHR, Moldovan and Others v. Romania, $\mathrm{n}^{\mathrm{o}} 41138 / 98$ and 64320/01, Judgment $\mathrm{n}^{\mathrm{o}} 2$ of 12 July 2005, para. 97.

${ }^{103}$ ECtHR, López Ostra v. Spain, no 16798/90, Judgment of 9 December 1994, para 51; ECtHR, Moldovan and Others $v$. Romania, $\mathrm{n}^{\circ} 41138 / 98$ and 64320/01, Judgment $\mathrm{n}^{\circ} 2$ of 12 July 2005, para. 97.

${ }^{104}$ KHOURY, Stéfanie, "Transnational Corporations and the European Court of Human Rights: Reflections on the Indirect and Direct Approaches to Accountability", Sortuz Oñati Journal of Emergent Socio-legal Studies, Vol. 4, no 1 (2010), p. 91 y ss.

105 Sentencia BVerfGE 7, 198 [Lüth].

${ }^{106}$ KHOURY, Loc. cit., p. 91.
} 
Spielmann sostiene que el texto del CEDH, en particular el art. $1^{107}$, proporciona el fundamento jurídico para el desarrollo de la doctrina de las obligaciones positivas que representa un instrumento de aplicación de los derechos, confiriendo una eficacia horizontal indirecta a las disposiciones sustantivas ${ }^{108}$. En la misma línea de ideas, el juez Garlicki afirma que el Convenio afecta a las relaciones privadas, independientemente de los requisitos del art. $34^{109}$. Deduce las obligaciones positivas llamadas a proteger los derechos de unas personas privadas contra la vulneración perpetrada por otras personas privadas. La deducción proviene de una serie de artículos (arts. 2, 8-11 y 13) cuyo enunciado abre la posibilidad de maniobra para la interpretación más generosa en el ámbito privado. También es cierto que el Tribunal no ha hecho uso de la "verdadera eficacia horizontal" 110 . Y, sin embargo, no se descarta del todo el "radiating" effect del $\mathrm{CEDH}$ en las relaciones entre particulares.

De este modo, aunque los particulares no pueden responder directamente por la vulneración del Convenio, el Tribunal tiene la facultad de constatar la implicación de estas en la violación de los derechos y las libertades protegidas ${ }^{111}$. Así, por ejemplo, en el caso Chipre c. Turquía ${ }^{112}$, el Tribunal considera que la aquiescencia o connivencia de las autoridades estatales en los actos de las personas privadas que infringen las disposiciones del Convenio puede acarrear la responsabilidad del Estado.

Parece particularmente relevante en el contexto de la actividad de las empresas, y especialmente las multinacionales, que la responsabilidad positiva del Estado no solo se concibe en relación con los actos con repercusión en el territorio de la jurisdicción estatal. Y es que el concepto de jurisdicción del art. 1 del CEDH no necesariamente se limita al territorio de las Partes concertantes. Excepcionalmente, el Tribunal admite la responsabilidad por los actos u omisiones cuyas repercusiones se producen fuera del territorio nacional ${ }^{113}$. La responsabilidad extraterritorial puede tener lugar en los

\footnotetext{
${ }^{107} \mathrm{El}$ art. 1 contiene la obligación de respetar los derechos humanos y reza: "Las Altas Partes Contratantes reconocen a toda persona bajo su jurisdicción los derechos y libertades definidos en el Título I del presente Convenio".

${ }^{108}$ SPIELMANN, Dean, "The European Convention of Human Rights. The European Court of Human Rights", in OLIVIER, Dawn and FEDTKE, Jörg (Eds.), Human Rights and the Private Sphere: A Comparative Study, Routledge-Cavendish, London, 2007, p. 428.

${ }^{109}$ GARLICKI, Lech, "Relations Between Private Actors and the ECHR", in SAJÓ, Andras and UITZ, Renata (Eds.), The Constitution in Private Relations, Eleven International Publishing, Utrecht, 2005, pp. 129 y ss.

110 "This does not mean, that the Court rejects the idea that the Convention has a 'radiating' effect on relations between private actors. Indeed, in the past thirty years there have been numerous examples of cases in which, as a matter of fact, the Court has been confronted with private actions violating the rights and liberties of other persons. In many of these cases it would have been possible, intellectually, to follow the German concept of 'indirect third party effect' to 'discover' the same concept in the 'living text' of the Convention and to draw from it some obligations of the Member States. However, the new Court, following the approach adopted by the earlier Court and Commission, simply did not want to develop the Convention in this direction". GARLICKI, Loc. cit., p. 142.

${ }^{111}$ POLAKIEWICZ, op. cit., p. 10.

${ }^{112}$ ECtHR, Cyprus v. Turkey, $\mathrm{n}^{\circ}$ 25781/94, Judgment of 10 May 2001, para. 81.

${ }^{113}$ Véase, entre otros, Kovačić and Others v. Slovenia, $\mathrm{n}^{\circ}$ 44574/98, 45133/98 and 48316/99, Decision on Admissibility of 1 April 2004; Ilaşcu and Others v. Moldova and Russia [GC], $\mathrm{n}^{\circ}$ 48787/99, Judgment of 8 July 2004, paras. 314 and 318; Issa and Others v. Turkey, $\mathrm{n}^{\circ}$ 31821/96, Judgment of 16 November 2004, paras. 68 and 71; Isaak v. Turkey, $\mathrm{n}^{\circ}$ 44587/98, Decision on Admissibility of 28 September 2006; Al Skeini
} 
siguientes supuestos: cuando el Estado en cuestión ejerce el control efectivo sobre un territorio extranjero, o una parte del territorio, o cuando ejerce control sobre individuos fuera de su territorio. No obstante, incluso en estas circunstancias, la responsabilidad de los actores no estatales se circunscribe en los límites de la doctrina de las obligaciones positivas, mencionada antes ${ }^{114}$.

En general, la responsabilidad de los Estados por violación de los derechos humanos por las empresas se limita al ámbito nacional y, con mayor frecuencia, tiene que ver con la alegación del art. 8 por los daños medioambientales. En muchos de los casos, el Tribunal ha condenado a los Estados en el contexto del artículo mencionado por no cumplir con sus obligaciones positivas de proteger a los individuos contra la actividad de las empresas privadas nociva para el medio ambiente ${ }^{115}$. Más en concreto, cabe hacer referencia a los casos López Ostra c. España y Guerra y otros c. Italia. En ambos, tiene lugar una contaminación del medio ambiente por empresas que provoca la vulneración del derecho al respeto de la vida privada y familiar del art. 8. Las sentencias correspondientes del TEDH condenan a los Estados por irregularidades en la regulación nacional, tales como una legislación deficiente o negligencia. Así, en el caso López Ostra, el Tribunal admite que, aunque los órganos estatales no pueden considerarse responsables directos de la contaminación, hay que reconocer que las autoridades de la ciudad en cuestión autorizaron la construcción de la fábrica en su territorio y el Estado financió la construcción $^{116}$. En el caso Guerra y otros, el problema reside en la falta de información sobre la contaminación por la empresa química ${ }^{117}$. Inicialmente, la demanda se fundó en la violación del art. 10 sobre la libertad de expresión. Se alegaba la falta de información para la población local sobre los factores de riesgo e instrucciones sobre la actuación en el supuesto de que acaeciese un accidente en la fábrica. Sin embargo, el Tribunal no siguió el razonamiento de la Comisión y admitió la demanda en base al art. 8, reconociendo que la obligación positiva forma parte del precepto.

El TEDH continuó la misma línea jurisprudencial en asuntos posteriores. En el caso Taskin c. Turquía, se aplicó el art. 8 al supuesto de un permiso concedido para la explotación de una mina con uso de sustancias contaminantes. En el caso Fadeeva c. Rusia, se acordó la responsabilidad de Rusia por la contaminación de la fábrica de acero Severstal. En el caso Giacomelli c. Italia, el Estado respondió por los daños medioambientales causados por el almacenamiento y tratamiento de los residuos ${ }^{118}$.

and Others v. the United Kingdom [GC], n55721/07, Judgment of 7 July 2011, paras.131 ff. Para más información, véase ECrHR, Extra-territorial jurisdiction of States Parties to the European Convention on Human Rights, Factsheet, July 2018, disponible en: https://www.echr.coe.int/Documents/FS_Extraterritorial_jurisdiction_ENG.pdf (visitado el 20 de abril de 2020).

${ }_{114}$ O’BRIEN, op. cit., pp. 62-63.

115 Véase, entre otros, los asuntos López Ostra v. Spain, no 16798/90, Judgment of 9 December 1994; Taşkin and Others v. Turkey, $\mathrm{n}^{\circ}$ 46117/99, Judgment of 10 December 2004; Fadeyeva v. the Russian Federation, $n^{\circ}$ 55273/00, Judgment of 9 June 2005; Tatar $v$. Romania, $\mathrm{n}^{\circ}$ 67021/01, Judgment of 27 January 2009; Vilnes and Others v. Norway, n ${ }^{\circ} 52806 / 09$ et al., Judgment of 5 December 2013.

${ }^{116}$ ECtHR, López Ostra v. Spain, no 16798/90, Judgment of 9 December 1994, para. 52.

${ }^{117}$ ECtHR, Guerra and Others v. Italy, no 14967/89, Judgment of 19 February 1998.

${ }^{118}$ ECtHR, Giacomelli v. Italy, n 59909/00, Judgment of 2 November 2006. 
En este sentido, poseen un estatus particular las compañías en propiedad del Estado o controladas por el Estado. En muchos países, este tipo de empresas representan una parte importante de la economía. Muy a menudo, dichas compañías dominan el sector energético, la extracción de recursos naturales, la agricultura, el transporte o las comunicaciones. Debido a la liberalización de los mercados, las empresas en propiedad del Estado se han trasformado de nacionales en transnacionales. Corroboran su importancia los datos estadísticos. Así, por ejemplo, en 2014, había cerca de 550 EMN en propiedad de los Estados, y el 70 por ciento de las inversiones chinas en la Unión Europea se habían realizado por este tipo de empresas ${ }^{119}$.

En cuanto a la posición del TEDH, los abusos de este tipo de empresas se han presentado en numerosos casos. En primer lugar, hay que determinar si la entidad en cuestión es una entidad pública por la que el Estado debe responder. Es el prerrequisito para la aplicación del art. 34. De manera alternativa, hay que verificar si la empresa posee una independencia institucional y operacional suficiente para que el Estado pueda ser exonerado de la responsabilidad por sus actos u omisiones ${ }^{120}$. En este sentido, el Tribunal puede tener en cuenta una serie de criterios, entre otros: el estatus legal de la compañía (por ejemplo, se ha constituido bajo el Derecho público o, como entidad independiente, bajo el Derecho privado); la naturaleza de su actividad (una función pública o una actividad comercial ordinaria); el contexto de su operación (por ejemplo, como un monopolio o negocio altamente regulado); la independencia institucional (el grado de participación del Estado), y la independencia operacional (el grado de la supervisión y el control estatal) ${ }^{121}$.

Según el criterio aplicado por el TEDH en el caso Yershova c. Rusia, el estatus jurídico de la empresa conforme al Derecho nacional, más en concreto, su constitución como una entidad independiente o privada, no se considera como determinante a los efectos del CEDH. En este supuesto, la demandante trabajó para una empresa municipal establecida bajo la legislación nacional como una entidad legalmente independiente. Dicha compañía no pagó a la demandante una cantidad en concepto de daños y perjuicios tras el despido. El TEDH acordó la responsabilidad del Estado con el fundamento en los siguientes aspectos: la compañía como tal y sus bienes eran de propiedad de los órganos municipales; prestaba servicios de vital importancia para la población, como uno de los principales proveedores de los servicios en cuestión; carecía de independencia, dado los fuertes vínculos institucionales con los órganos municipales y las limitaciones en el uso de sus activos, y las autoridades de la ciudad aprobaban todas las transacciones que

\footnotetext{
${ }^{119}$ O'BRIEN, op. cit., p. 33.

120 Mykhaylenky and Others v. Ukraine, nos. 35091/02, 35196/02, 35201/02, 35204/02, 35945/02, 35949/02, 35953/02, 36800/02, 38296/02 and 42814/02, paras. 43-46, ECHR 2004-XII; Cooperativa Agricola Slobozia Hanesei v. Moldova, $\mathrm{n}^{\circ}$ 39745/02, paras. 17-19, Judgment of 3 April 2007; Yershova v. Russia, n 1387/04, paras. 54-63, Judgment of 8 April 2010; Ališić and Others v. Bosnia and Herzegovina, Croatia, Serbia, Slovenia and the Former Yugoslav Republic of Macedonia [GC], $\mathrm{n}^{\circ}$ 60642/08, Judgment of 16 July 2014, para. 114.

${ }^{121}$ ECtHR, Ališić and Others v. Bosnia and Herzegovina, Croatia, Serbia, Slovenia and the Former Yugoslav Republic of Macedonia [GC], nº 60642/08, Judgment of 16 July 2014, para. 114; COUNCIL OF EUROPE, Explanatory Memorandum, para. 39; O'BRIEN, op. cit., p. 35.
} 
afectaban a la propiedad de la compañía, controlaban su administración y dirección y decidían sobre la continuidad o liquidación de su actividad ${ }^{122}$.

La obligación positiva de los Estados de proteger a las personas contra los efectos nocivos de la actividad de las empresas se complementa con las obligaciones procesales que requieren, una vez producida la violación, llevar a cabo una investigación oficial independiente, imparcial, adecuada y pronta. Además, las autoridades tienen que establecer los mecanismos que permitan a las víctimas de dichas vulneraciones de derechos humanos obtener una reparación rápida y adecuada por los daños causados.

Sin duda, la legitimación activa de las empresas y, en particular, de las EMN, debería tener, como contrapartida, la responsabilidad. No en vano, sus actividades económicas traspasan los límites de los Estados y producen efectos transnacionales. Existen propuestas al respecto, que se fundamentan en las disposiciones del $\mathrm{CEDH}$, por ejemplo, el art. 17, que prohíbe el abuso del derecho, e impide que el Convenio se interprete en el sentido de implicar para un Estado, un grupo o individuo, un derecho cualquiera a dedicarse a una actividad o a realizar un acto tendente a la destrucción de los derechos o libertades protegidos ${ }^{123}$. Parece que dicho artículo puede servir de fundamento para la responsabilidad de "cualquier persona", incluida la empresa. Por su parte, la labor interpretativa del Tribunal ha contribuido al carácter vivo y dinámico del Convenio ${ }^{124}$. El ex juez del TEDH Loucaides sostuvo que una aproximación dinámica a la aplicación del CEDH implica que se tengan en cuenta las tendencias políticas y económicas y los cambios en la vida cotidiana que pueden alterar el significado de los mismos conceptos en el momento de la adopción y la entrada en vigor del Convenio ${ }^{125}$.

Sin embargo, la práctica del Tribunal ha reflejado cierta cautela a la hora de entrar en el debate sobre el papel de las empresas para la protección de los derechos humanos. Así, en opinión de Verdonck, se desaprovechó una oportunidad importante de pronunciarse al respecto con motivo del asunto Özel c. Turquía ${ }^{126}$.

\section{Conclusiones.}

La multiplicación de los actores y la creciente complejidad de las relaciones internacionales contribuye a la necesidad de revisar la atribución de la personalidad jurídica internacional únicamente a los Estados y a las OO.II. Desde la perspectiva pragmática, dicha revisión puede encontrar su fundamento en la existencia fáctica de los

\footnotetext{
${ }^{122}$ ECtHR, Yershova v. Russia, no 1387/04, Judgment of 8 April 2010, paras. 56-58.

${ }^{123}$ KHOURY, Loc. cit., p. 79.

124 "The Court must ... recall that the Convention is a living instrument which, as the Commission rightly stressed, must be interpreted in the light of present-day conditions". ECtHR, Tyrer v. the United Kingdom, $\mathrm{n}^{\circ} 5856 / 72$, Judgment of 25 April of 1978, para 31.

${ }^{125}$ LOUCAIDES, Loukis G., The European Convention on Human Rights: Collected Essays, Martinus Nijhoff Publishers, The Hague, Boston, London, 2007, p. 13; KHOURY, Loc. cit., p. 82.

${ }^{126}$ ECtHR, Özel and Others v. Turkey, n ${ }^{\circ} 14350 / 05,15245 / 05$ and 16051/05, Judgment of 17 November 2015. Véase VERDONCK, Lieselot, "How the European Court of Human Rights evaded the Business and Human Rights Debate in Özel v. Turkey”, The Turkish Commercial Law Review, Vol. 2, n 1(2016), pp. 111-118.
} 
elementos de la subjetividad internacional en otros actores, incluidas las empresas y, en especial, las multinacionales. Así, el art 34 del CEDH atribuye a las empresas la legitimación activa ante el TEDH.

De este modo, puede observarse que los elementos detectados se deben a la interacción de los actores mencionados con los sujetos reconocidos del Derecho internacional. Esta práctica también indica que, en última instancia, son los Estados quienes aseguran los derechos y las obligaciones internacionales de otros entes, y que el Derecho internacional de los derechos humanos se perfila como un ámbito particularmente propicio para la cristalización de la subjetividad internacional de otros actores relevantes.

Existe un constante ir y venir en el carácter estatocéntrico de la protección de los derechos humanos y la responsabilidad por su violación. En estos momentos marcados por la crisis sanitaria, al igual que en la todavía reciente situación de la crisis financiera y económica, el protagonismo de los Estados parece volver a cobrar relevancia frente al papel de otros actores en el panorama internacional. Sin embargo, en el supuesto de las EMN, sigue vigente el argumento del importante poder económico que traspasa las fronteras. A muchas de ellas, puede aportar un beneficio aún mayor su potencial tecnológico y su capacidad de restructuración y reorganización de las actividades para hacer frente a las nuevas necesidades de los mercados. Valga hacer referencia a Amazon, una EMN con la cadena logística más sofisticada jamás diseñada ${ }^{127}$.

Se ha observado que tanto los instrumentos no vinculantes del Comité de Ministros del Consejo de Europa, como la jurisprudencia del TEDH admiten la responsabilidad de las empresas de manera indirecta, esto es, en el plano nacional, y asegurada por el Estado. El mismo paradigma se perfila en el Proyecto de un Tratado sobre las Empresas y Derechos Humanos de la ONU. El art. 6 relativo a la responsabilidad encomienda a los Estados que, en su legislación nacional, garanticen un sistema adecuado e integral de responsabilidad jurídica por violaciones o abusos a los derechos humanos en el contexto de la actividad empresarial, incluyendo la de carácter transnacional (parr.1). Esta disposición comprende medidas de responsabilidad civil, penal y administrativa, distintas de la responsabilidad de las personas físicas. Además, los Estados deben prever unas sanciones efectivas, proporcionadas y disuasorias y la reparación a las víctimas por los daños y perjuicios causados por la actividad empresarial (párr. 4).

El TEDH exige la responsabilidad de los Estados por la vulneración de los derechos humanos cometidos por las empresas en su jurisdicción, en particular, por daños

\footnotetext{
${ }^{127}$ Desde que ha empezado la pandemia, su plataforma tuvo un $32 \%$ más de visitas que el año anterior. Está procesando entre un $10 \%$ y un $40 \%$ más de los paquetes habituales para esta época del año. Recientemente, ha contratado 100.000 trabajadores más. El banco de inversión Morgan Stanley estima que este año ingresará un 22,8\% más de beneficios: cfr. GARCÍA VEGA, Miguel Ángel, "Y el ganador de la crisis es... Jeff Bezos". El gigante de la distribución Amazon se ha convertido en un refugio donde comprar y la fortuna de su presidente y fundador se ha incrementado en casi 30.000 millones en el último mes, El País, 25 de abril de 2020. Con todo, según otras informaciones, el aumento de las ventas no se ha traducido en unos mayores beneficios: cfr. JIMÉNEZ, Marimar y SANZ SÁCHEZ DE ROJAS, Fernando, "Amazon ingresa en su primer trimestre 68.877 millones, un 26\% más, pero gana un 29\% menos", El País, 1 de mayo de 2020.
} 
medioambientales, en el contexto de la aplicación del art. 8 del CEDH. En primer lugar, se trata de la responsabilidad por las actividades nocivas de las empresas en propiedad del Estado o controladas por el Estado. En segundo lugar, en virtud de la técnica de las obligaciones positivas, se concibe la responsabilidad por no adoptar medidas para la protección efectiva de los derechos humanos, incluso en el ámbito de las relaciones entre los particulares.

Sin duda, en el sistema del Consejo de Europa, provoca un cierto desequilibrio el hecho de que las empresas y las EMN puedan demandar por la violación de los derechos humanos del CEDH, pero no responden directamente ante el TEDH. Según la estadística disponible hasta 2014, el 5\% de las demandas las presentaron las empresas. Este argumento se complementa con la premisa de carácter político y moral de que las grandes beneficiarias de la economía deberían responder, al menos in solidum o subsidiariamente, de las actividades que les aportan sus beneficios ${ }^{128}$.

Sin embargo, hoy en día, resulta inviable plantear su responsabilidad directa en el plano internacional. Este planteamiento abriría la vía a la responsabilidad de otros actores con legitimación activa (por ejemplo, las personas físicas y las ONGs), atentaría contra la soberanía de los Estados y convertiría al TEDH en una suerte de órgano de casación de los altos tribunales nacionales.

En cambio, parece oportuno reforzar los mecanismos de la responsabilidad indirecta, en particular, la responsabilidad extraterritorial del Estado por la actividad empresarial de los sujetos en su jurisdicción, cuyos ejemplos ya contempla la práctica jurisdiccional del TEDH en otros contextos.

\section{Bibliografía.}

ADDO, Michael K. (Ed.), Human Rights Standards and the Responsibility of Transnational Corporations, Kluwer Law International, The Hague, 1999.

AIRA GONZÁLEZ, Patricia, "Reflexiones jurídicas en torno a la consideración de la empresa multinacional como sujeto del derecho internacional”, Revista de Derecho de la UNED, nº 20 (2017), pp. 237-261.

ANDRÉS SÁENZ DE SANTA MARÍA, Paz, "Las dinámicas del Derecho internacional en el siglo XXI: acordes y desacordes", en MARTÍN Y PÉREZ DE NANCLARES, Javier (Coord.), Estados y organizaciones internacionales ante las nuevas crisis globales, AEPDIRI, Iustel, Universidad de Rioja, 2010.

\footnotetext{
128 SERVAIS, Jean-Michel, "Préface", en DAGRON, Stéphanie ; DUPONT, Anne-Sylvie et LEMPEN, Karine (Eds.), L'OIT et le droit social en Suisse : 100 ans et àpres ? Acts du colloque organisé par le Pôle Berenstein à l'occasion des 100 ans de l'Organisation Internationale du Travail, Pôle Berenstein, Faculté de droit, Univertité de Genève, Genève, 2019, p. 4.
} 
BAYLOS, Antonio, "Un instrumento de regularización: Empresas transnacionales y acuerdos marco globales", Cuadernos de Relaciones Laborales, Vol. 27, n 1(2009), pp. 107-125.

BELLACE, Janice R. and TER HAAR, Beryl (Eds), Research Handbook on Labour, Business and Human Rights Law, Edward Elgar Publishing, Cheltenham, Northampton, 2019.

BUENO, Nicolas, "Multinationas Enterprases and Labour Rights: Concepts and Implementation", in BELLACE, Janice R. and TER HAAR, Beryl (Eds), Research Handbook on Labour, Business and Human Rights Law, Edward Elgar Publishing, Cheltenham, Northampton, 2019, pp. 421-438.

CARMONA CUENCA, Encarnación, "Derechos sociales de prestación y obligación positiva del Estado en la jurisprudencia del Tribunal Europeo de Derechos Humanos", Revista de Derecho Político, no 100 (2017), pp. 1209-1238.

CRAWFORD, James, Brownlie's Principles of Public International Law, $8^{\text {th }}$ ed., Oxford University Press, Oxford 2012.

DIEZ DE VELASCO, Manuel, Instituciones de Derecho Internacional Público, $17^{\mathrm{a}}$ ed., Tecnos, Madrid, 2009.

EMBERLAND, Marius, "The Corporate Veil in the Case Law of the European Court of Human Rights”, ZaöRV, 63 (2003), pp. 945-969.

EMBERLAND, Marius, The Human Rights of Companies: Exploring the Structure of ECHR Protection, Oxford University Press, Oxford, 2006.

GARLICKI, Lech, "Relations Between Private Actors and the ECHR", SAJÓ, Andras and UITZ, Renata (Eds.), The Constitution in Private Relations, Eleven International Publishing, Utrecht, 2005, pp. 129-144.

GARRIDO GÓMEZ, María Isabel, Las Transformaciones del Derecho en la Sociedad Global, Thomson Reuters, Aranzadi, Cizur Menor, 2010.

GIL Y GIL, J. L. (Dir.), España y la OIT. 100 años de diálogo en un mundo cambiante, Ediciones Cinca, Madrid, 2017.

GOSALBO BONO, Ricardo, "Consideraciones en torno a la distinción entre el fondo y la forma en el Derecho internacional (público y privado)", REDI, Vol. 71, no 1 (2019), pp. 23-62.

FARINELLA, Favio, Sujetos del Derecho Internacional. Una revisión a la luz de los Derechos Humanos, Ed. Eudem, Mar del Plata, 2013.

HABERMAS, Jurgen, Facticidad y validez. Sobre el Derecho y el Estado democrático de Derecho en términos de teoría del discurso, Trotta, Madrid, 2008.

HABREMAS, Jurgen, The Crisis of the European Union. A Response, Polity Press, Cambridge, 2012. 
HARRIS, David; O'BOYLE, Michael; BATES, Ed and BUCKLEY, Carla (Eds.), Harris, O'Boyle, and Warbrick: Law of the European Convention on Human Rights, $4^{\text {th }}$ Edition, Oxford University Press, Oxford, 2018.

HERNÁNDEZ ZUBIZARRETA, Juan, Las empresas transnacionales y los derechos humanos: Historia de una simetría normativa. De la responsabilidad social corporativa a las redes contrahegemómicas transnacionales, Hegoa, Bilbao 2009. ttt

HICKEY Jr., James E., "The Source of International Legal Personality in the $21^{\text {st }}$ Century", 2 Hofstra L.\&Pol'y Symp 1 (1997), available at: http://scholarlyco mmons.law.hofstra.edu/faculty_scholarship/563

KARAVIAS, Markos, "Shared Responsibility and Multinational Enterprises", Neth Int Law Rev, 62 (2015), pp. 91-117.

KAVANAUGH, Kathleen A., "Policing the Margins: Rights Protection and the European Court of Human Rights", European Human Rights Law Review, n 4(2006), p. 422-444.

KHOURY, Stéfanie, "Transnational Corporations and the European Court of Human Rights: Reflections on the Indirect and Direct Approaches to Accountability", Sortuz. Oñati Journal of Emergent Socio-legal Studies, Vol. 4, nº 1 (2010), pp. 68-110.

KU, Julian G., "The Limits of Corporate Rights under International Law", Chicago Journal of International Law, Vol. 12, no 2(2012), pp.729-753.

LANTARÓN BARQUÍN, David, “¿Hacia un sistema 'cosmopolita’ de fuentes del Derecho del Trabajo? La empresa multinacional como detonante del cambio", Trabajo y derecho: nueva revista de actualidad y relaciones laborales, ${ }^{\circ} 10$ Extra (2019), 29 pp.

LOUCAIDES, Loukis G., The European Convention on Human Rights: Collected Essays, Martinus Nijhoff Publishers, The Hague, Boston, London, 2007.

MADELAINE, Colombine, La technique des obligations positives en droit de la Convention Européenne des Droits de l'Homme, Paris, Dalloz, 2014.

MARTÍN ORTEGA, Olga, Empresas Multinacionales y Derechos Humanos en Derecho internacional, Ed. Bosch, Barcelona, 2007.

MARTÍN Y PÉREZ DE NANCLARES, José (Coord.), Estados y organizaciones internacionales ante las nuevas crisis globales, AEPDIRI, Iustel, Universidad de Rioja, 2010.

MONEREO PÉREZ, José Luis, "La racionalización jurídica de las relaciones laborales y la emergencia de nuevas fuentes reguladoras en el orden internacional", Lex Social. Revista Jurídica de los Derechos Sociales, Vol. 8, nº 1 (2018), 44 pp.

MUCHLINSKI, Peter T., Multinational Enterprises and the Law, $2^{\text {nd }}$ Ed., Oxford University Press, Oxford, 2007.

NIJMAN, Janne E., The Concept of International Legal Personality: An Inquiry into the History and Theory of International Law, T.M.C. Asser Press, The Hague, 2004. 
NINO, Michele, "El análisis del land grabbing a la luz de la norma internacional de la soberanía territorial”, REDI, Vol. 71, nº 1 (2019), pp. 215-221.

O'BRIEN, Claire Methven, Business and Human Rights. A handbook for legal practitioners, November 2018, Council of Europe, Strasbourg, 2018.

POLAKIEWICZ, Jörg, Corporate Responsibility to Respect Human Rights: Challenges and Opportunities for Europe and Japan, Nagoya University, publicado el 1 de octubre de 2012, pp. 1-83.

PORTMANN, Roland, Legal Personality in International law, Cambridge University Press, Cambridge, 2010.

PRONER, Carol; OLÁSOLO, Héctor; VILLÁN DURÁN, Carlos; RICOMB, Giselle, y BACK, Charlotte (Coords.), $70^{\circ}$ aniversario de la Declaración Universal de Derechos Humanos. La protección internacional de los derechos humanos en cuestión, Tirant lo Blanch, Valencia, 2018.

RODRÍGUEZ-PIÑERO Y BRAVO-FERRER, Miguel, "Los cambios en el mundo del trabajo y su respuesta jurídica», Relaciones Laborales: Revista crítica de teoría y práctica, no 9 (2007), pp. 113-126.

RODRÍGUEZ-PIÑERO Y BRAVO-FERRER, Miguel, "La difícil coyuntura del Derecho del Trabajo", Relaciones laborales: Revista crítica de teoría y práctica, $\mathrm{n}^{\circ} 2$ (2011), pp. 75-87.

SANGUINETI RAYMOND, Wilfredo, "Los límites del poder privado de las empresas multinacionales", Trabajo y derecho: nueva revista de actualidad y relaciones laborales, n 10 Extra (2019), 9 pp.

SERVAIS, Jean-Michel, "Préface", en DAGRON, Stéphanie ; DUPONT, Anne-Sylvie et LEMPEN, Karine (Eds.), L'OIT et le droit social en Suisse : 100 ans et àpres ? Acts du colloque organisé par le Pôle Berenstein à l'occasion des 100 ans de l'Organisation Internationale du Travail, Pôle Berenstein, Faculté de droit, Univertité de Genève, Genève, 2019, pp. 1-6.

SPIELMANN, Dean, "The European Convention of Human Rights. The European Court of Human Rights", in OLIVIER, Dawn, and FEDTKE, Jörg (Eds.), Human Rights and the Private Sphere: A Comparative Study, Routledge-Cavendish, London, 2007, p. $427-$ 464.

SUSI, Mart, "Delfi A.S. v. Estonia", in "International decisions", American Journal of International Law, Vol. 108 (2014), pp. 295-302.

USHAKOVA, Tatsiana, "El caso Yukos desde la óptica multidimensional, con especial referencia a los problemas de competencia", Revista de arbitraje comercial y de inversiones, Vol. VIII, $\mathrm{n}^{\circ} 1$ (2015), pp. 123-170. 
USHAKOVA, Tatsiana, "La OIT como una organización internacional dinámica en el sistema de Derecho internacional”, en Gil y Gil, J. L. (Dir.), España y la OIT. 100 años de diálogo en un mundo cambiante, Ediciones Cinca, Madrid 2017, pp. 59-103.

USHAKOVA, Tatsiana, "Las empresas y la protección de los derechos humanos en el sistema del Consejo de Europa", Revista Internacional Consinter de Direito, $2^{\circ}$ Semestre, Vol. VII (2018), pp. 359-376.

VALDÉS DAL-RÉ, Fernando, "Soft law, Derecho del trabajo y orden económico globalizado", Relaciones Laborales: Revista crítica de teoría y práctica, nº (2005), pp. 37-54.

VAN AAKEN, Anne; MOTOC, Iulia (Eds.), The European Convention on Human Rights and General International Law, Oxford University Press, Oxford, 2018.

VAN DEN MUIJSENBERGH, Winfried H. A. M. and REZAI, Sam, "Corporations and European Convention on Human Rights", 25 Pac. McGeorge Global Bus. \& Dev. L.J. (2012), pp. 43-68, available at: https://scholarlycommons.pacific.edu/globe/vol25/iss1/5.

VAN KEMPEN, Piet Hein, "Human Rights and Criminal Justice Applied to Legal Persons. Protection and Liability of Private and Public Juristic Entities under the ICCPR, ECHR, ACHR and AfChHPR", Electronic Journal of Comparative Law, Vol. 14, $\mathrm{n}^{\circ} 3$ (2010), available at: http://wwwejcl.org.

VERDONCK, Lieselot, "How the European Court of Human Rights evaded the Business and Human Rights Debate in Özel v. Turkey”, The Turkish Commercial Law Review, Vol. 2, no 1(2016), pp. 111-118.

WORSTER, William T., "Relative International Legal Personality of Non-State Actors", Brook. J. Int'l L., Vol. 42, n 1(2016), pp. 206-273. 